\title{
CDC2/SPDY transiently associates with endoplasmic reticulum exit sites during oocyte maturation
} Jurriaan J Hölzenspies ${ }^{1,2}$, Willem Stoorvogel ${ }^{2}$, Ben Colenbrander ${ }^{1}$, Bernard AJ Roelen ${ }^{1}$, Dagmar R Gutknecht ${ }^{3}$ and Theo van Haeften*2

Address: ${ }^{1}$ Department of Farm Animal Health, Faculty of Veterinary Medicine, Utrecht University, Utrecht, the Netherlands, ${ }^{2}$ Department of Biochemistry \& Cell Biology, Faculty of Veterinary Medicine, Utrecht University, Utrecht, the Netherlands and ${ }^{3}$ Department of Reproductive Medicine, University Medical Centre, Utrecht, the Netherlands

Email: Jurriaan J Hölzenspies - j.j.holzenspies@uu.nl; Willem Stoorvogel - w.stoorvogel@uu.nl; Ben Colenbrander - b.colenbrander@uu.nl; Bernard AJ Roelen - b.a.j.roelen@uu.nl; Dagmar R Gutknecht - d.r.gutknecht@umcutrecht.nl; Theo van Haeften* - t.vanhaeften@uu.nl

* Corresponding author

Published: 3 February 2009

BMC Developmental Biology 2009, 9:8 doi:10.1 I86/I47I-2I3X-9-8

This article is available from: http://www.biomedcentral.com/l47/-2/3X/9/8

(c) 2009 Hölzenspies et al; licensee BioMed Central Ltd.

This is an Open Access article distributed under the terms of the Creative Commons Attribution License (http://creativecommons.org/licenses/by/2.0), which permits unrestricted use, distribution, and reproduction in any medium, provided the original work is properly cited.

\begin{abstract}
Background: Mammalian oocytes acquire competence to be fertilized during meiotic maturation. The protein kinase CDC2 plays a pivotal role in several key maturation events, in part through controlled changes in $C D C 2$ localization. Although $C D C 2$ is involved in initiation of maturation, a detailed analysis of $C D C 2$ localization at the onset of maturation is lacking. In this study, the subcellular distribution of CDC2 and its regulatory proteins cyclin B and SPDY in combination with several organelle markers at the onset of pig oocyte maturation has been investigated.
\end{abstract}

Results: Our results demonstrate that $C D C 2$ transiently associates with a single domain, identified as a cluster of endoplasmic reticulum (ER) exit sites (ERES) by the presence of SEC23, in the cortex of maturing porcine oocytes prior to germinal vesicle break down. Inhibition of meiosis resumption by forskolin treatment prevented translocation of CDC2 to this ERES cluster. Phosphorylated GMI30 (P-GMI30), which is a marker for fragmented Golgi, localized to ERES in almost all immature oocytes and was not affected by forskolin treatment. After removal of forskolin from the culture media, the transient translocation of CDC2 to ERES was accompanied by a transient dispersion of P-GMI 30 into the ER suggesting a role for $C D C 2$ in redistributing Golgi components that have collapsed into ERES further into the ER during meiosis. Finally, we show that SPDY, rather than cyclin B, colocalizes with CDC2 at ERES, suggesting a role for the CDC2/SPDY complex in regulating the secretory pathway during oocyte maturation.

Conclusion: Our data demonstrate the presence of a novel structure in the cortex of porcine oocytes that comprises ERES and transiently accumulates CDC2 prior to germinal vesicle breakdown. In addition, we show that SPDY, but not cyclin B, localizes to this ERES cluster together with CDC2.

\section{Background}

Fully grown immature mammalian oocytes are arrested at the diplotene stage of meiotic prophase I. Oocyte matura- tion is initiated in vivo when the mural granulosa cells respond to the preovulatory luteinizing hormone surge, or in vitro when oocytes are isolated from follicles [1]. 
Germinal vesicle breakdown (GVBD) marks the onset of nuclear maturation, which progresses into formation of the first metaphase spindle, followed by extrusion of the first polar body and formation of the second metaphase spindle. At metaphase II, oocytes enter a second period of meiotic arrest, which is maintained until fertilization. Meiosis resumption is often characterized by the occurrence of GVBD, since this is the first clear morphological event that takes place after release from meiotic inhibition. However, extensive rearrangements of components within the ooplasm, known as cytoplasmic maturation [2], already start to occur prior to GVBD [3].

Cytoplasmic maturation includes dynamic changes in the distribution and integrity of the Golgi apparatus and endoplasmic reticulum (ER) [4-6]. In somatic cells, the Golgi apparatus is fragmented at the onset of mitosis and starts to reform at telophase [7]. Two distinct views on the mechanism of Golgi partitioning during mitotis have been proposed $[7,8]$. One view holds that association of Golgi fragments with the metaphase spindle allows equal partitioning of Golgi components into the two daughter cells [9-11]. The second view is based on the idea of a dynamic Golgi apparatus, in which Golgi proteins continuously cycle through the ER. Coat protein II (COPII)coated vesicles that traffic from ER to Golgi originate at subdomains of the ER, known as ER exit sites (ERES). Vesicle formation at ERES is inhibited during mitosis as a consequence of which cycling Golgi proteins become trapped in the ER [12]. Golgi components are then equally distributed into daughter cells together with the ER and the Golgi is reformed from vesicles that form at ERES when the ER export block is lifted at telophase $[13,14]$. Although the general distribution of ER during oocyte maturation has been studied extensively [15], a function for ERES during oocyte maturation remains to be elucidated. Evidence for a role of either of these two mechanisms in the control of Golgi dynamics during oocyte meiosis is lacking. It is clear that cytoplasmic processes constitute an integral part of both mitosis and meiosis, and we therefore use the term 'meiosis resumption' to indicate the moment when the first rearrangement of components occurs within the oocyte in response to release from the inhibitory influence of the follicular environment.

In most cells, cell division cycle 2 (CDC2, also referred to as cyclin-dependent kinase 1) complexes with cyclin B to form M-phase promoting factor (MPF), a well known central regulator of both mitotic and meiotic events. MPF regulates chromosome condensation, nuclear envelope breakdown, and formation of metaphase spindles in both somatic cells and oocytes, whereas transition from metaphase to anaphase requires inactivation of MPF [16]. In mitotic cells, disassembly of Golgi and ERES are regulated by CDC2 through phosphorylation of GM130 and p47, respectively $[17,18]$. Despite the similarities in CDC2 functions during mitosis and meiosis, it is unclear whether the activity of CDC2 exerts a similarly stringent control over the integrity of the Golgi apparatus and ERES in oocytes as it does in mitotic cells.

The activity of CDC2 during the meiotic divisions of porcine oocytes is known to be controlled by at least two regulatory proteins, i.e. cyclin B and speedy (SPDY) $[19,20]$. SPDY proteins have no homology to cyclins, but are potent activators of CDC2 during early phases of oocyte maturation [21]. CDC2 activity can alternatively be controlled through phosphorylation of specific residues. Compared to the CDC2/cyclin B complex, the activity of CDC2 when complexed with SPDY is less sensitive to phosphorylation [19]. Finally, CDC2 activity may be regulated by changing the subcellular distribution of CDC2 and/or its regulators [22]: Sequestration of CDC2 to subcellular domains may prevent CDC2 from phosphorylating specific substrates or limit access of regulatory proteins to CDC2. Conversely, concentration of CDC2 at subcellular 'foci', such as the Golgi or ERES, could confer spatio-temporal specificity to CDC2 function.

To establish the role of the subcellular (re-)distribution of CDC2, and its regulatory proteins cyclin B and SPDY, in the regulation of early oocyte maturation, we examined their localization and the distribution of cell organelles containing potential CDC2 target proteins during pig oocyte maturation. The localization of these organelles was investigated using antibodies raised against the ERES marker SEC23, the Golgi marker GM130, and phosphorylated GM130 (P-GM130), a marker for fragmented Golgi. Our results demonstrate that CDC2 transiently associates with a P-GM130-labeled structure in the cortex of maturing porcine oocytes prior to GVBD. Using the ERES marker SEC23, we show that this structure consists of a cluster of ERES. Furthermore, our data on the distribution of CDC2 and its regulatory protein SPDY in oocytes suggest a role for the CDC2/SPDY complex in regulation of secretion during oocyte maturation.

\section{Results CDC2 accumulates in a single cortical structure in GV stage oocytes}

To determine the subcellular distribution of CDC2, oocytes were fixed after 0 or $24 \mathrm{~h}$ of in vitro maturation (IVM), immuno-labeled and analyzed by confocal laser scanning microscopy. At $0 \mathrm{~h}$, we observed a single large CDC2-containing cytoplasmic structure in the cortex of 25\% of GV oocytes (Fig. 1A). High magnification images showed that this CDC2-positive structure was composed of clustered smaller units (Fig. 1A'). Additionally, 35\% of oocytes displayed CDC2 staining in the GV (Fig. 1B), a 

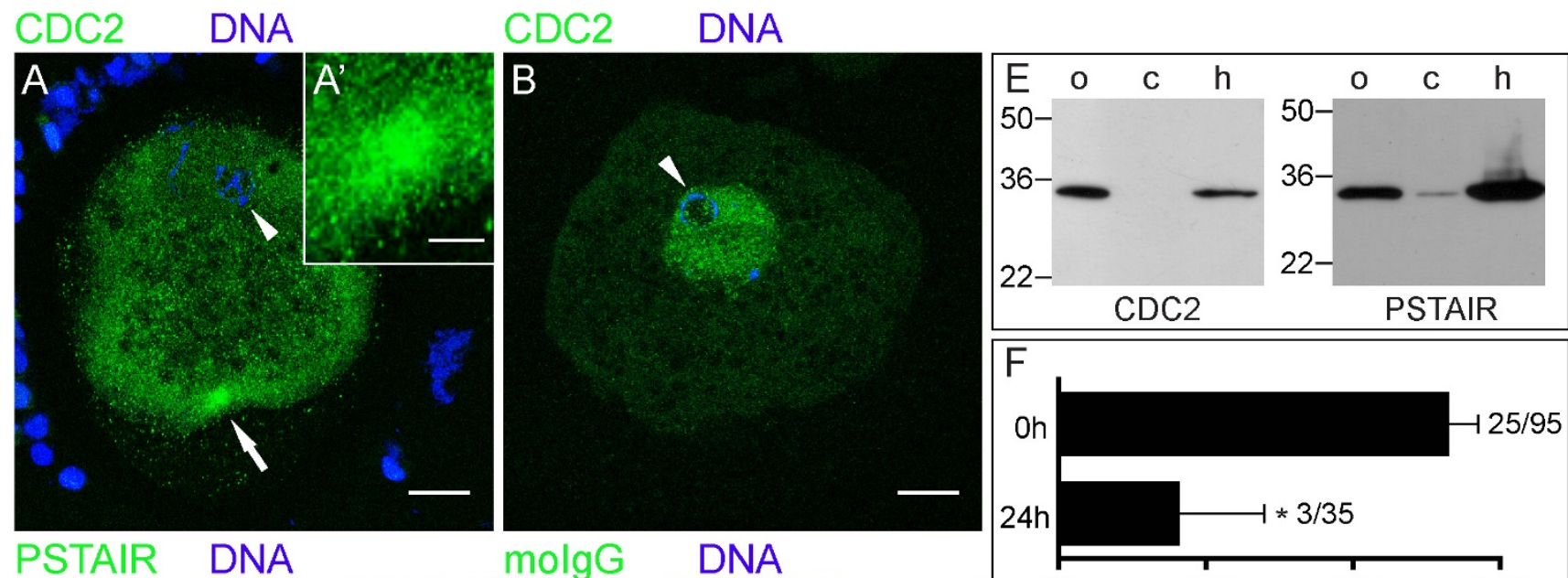

moln
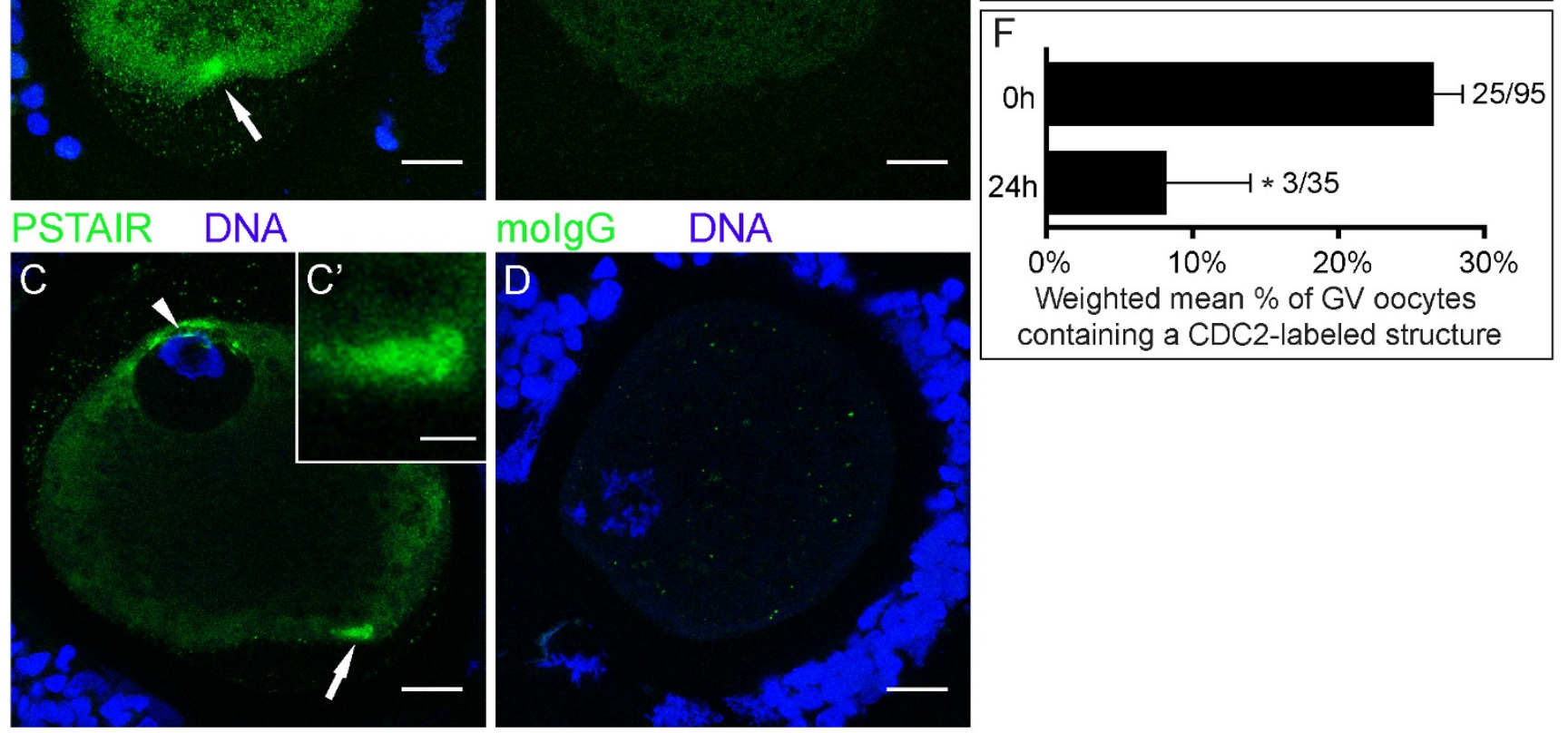

\section{Figure I}

CDC2 accumulates in a single cortical structure in GV stage oocytes. (A, B) 0 h GV stage oocytes labeled for CDC2 (green) and DNA (blue) showing CDC2-accumulation in the cortex of the oocyte (A) and in the GV (B). (C) 0 h GV stage oocyte showing PSTAIR labeling (green) and DNA (blue). PSTAIR also accumulates in a cortical domain. Arrows indicate the area that is shown enlarged in the insets $\left(A^{\prime}, C^{\prime}\right)$, and arrowheads denote the GV. (D) $0 \mathrm{~h}$ GV stage oocyte from the same experiment as the oocyte in A, labeled with mouse IgG (molgG; green) and DNA marker (blue). The image was produced using the same confocal settings and enhancements as in A. All images are Z-projections of 3 consecutive confocal sections. Scale bars represent $20 \mu \mathrm{m}$ in A-D, and $5 \mu \mathrm{m}$ in $A^{\prime}$ and $C^{\prime}$. (E) Western blot of CDC2 and PSTAIR on 250 oocytes (o) and cumulus cells (c) collected during the denuding procedure of these oocytes showing a specific band at $\sim 34 \mathrm{kDa}$. A HeLa cell lysate $(\mathrm{h})$ was used as positive control. Molecular weight $(\mathrm{kDa})$ is indicated on the left of each set of lanes. $(\mathrm{F}) \mathrm{Weighted}$ mean percentage \pm weighted SEM of GV stage oocytes that contained a CDC2-labeled cortical domain at 0 and 24 hours of maturation in 3 independent experiments. Absolute numbers are indicated to the right of the bars (number of positive oocytes/total number of oocytes) and $*$ denotes significant difference $(\mathrm{P}<0.05)$.

pattern that rarely coincided with staining in a cortical structure. Staining with an anti-PSTAIR antibody (Fig. 1C, $\left.\mathrm{C}^{\prime}\right)$, which recognizes the cyclin-binding domain that is conserved in all CDKs, including CDC2 [23], showed a morphologically identical structure. As could be expected from a broader specificity, PSTAIR-reactive antibodies also labeled other intracellular areas, e.g. cytoplasmic areas near the GV at the plasma membrane of the oocyte (Fig. 1C). Labeling with control IgG from pre-immune serum revealed sporadic non-specific small puncta (Fig. 1D). Specificity of the CDC2 and PSTAIR directed anti- bodies was further supported by immunoblotting, which revealed a single specific band at the expected $34 \mathrm{kDa}$ molecular weight in oocyte and HeLa cell lysates. Little if any CDC2 and PSTAIR could be detected in the cumulus cells isolated from cumulus-oocyte complexes, which is probably due to low mitotic activity of these cells (Fig. $1 \mathrm{E})$.

The rate of oocyte maturation in our experimental system was consistent with those previously reported in IVM studies using similar maturation conditions [24]: All 
oocytes were in GV stage directly after isolation $(0 \mathrm{~h} ; \mathrm{n}=$ $103)$; after $24 \mathrm{~h}$ of culture $(\mathrm{n}=67), 39 \pm 5 \%$ of oocytes were still in GV, while $61 \pm 5 \%$ had progressed to MI or MII; after $44 \mathrm{~h}$ of maturation $(n=56), 88 \pm 4 \%$ of oocytes were in MII stage. The association of CDC2 with the cortical structure depended on the state of oocyte maturation, since the percentage of GV oocytes containing a CDC2labeled structure was significantly reduced from $26 \pm 2 \%$ at $0 \mathrm{~h}$ to $9 \pm 6 \%$ at $24 \mathrm{~h}$ of IVM (Fig. 1F), while this CDC2labeled structure was not observed in any oocytes that had progressed to MI or MII. Taken together, these data demonstrate that CDC2 associates with a single cortical structure prior to GVBD and suggest that this association is transient.

\section{CDC2 associates with ER exit sites}

To identify the nature of these CDC2-labeled structures, immature $(0 \mathrm{~h})$ oocytes were double-labeled for CDC2 and several other markers: SEC23, GM130, P-GM130, calnexin, gamma-tubulin, NUP153, and mitotracker (see Table 1). SEC23 is a component of the COPII complex, which is involved in the formation of transport vesicles at ERES. COPII-coated vesicles transfer cargo from ER to Golgi and dissociate their coat after fission from ERES. In $0 \mathrm{~h} \mathrm{GV}$ oocytes, half of the CDC2-labeled structures were positive for SEC23 (Fig. 2A-C; IgG controls are shown in D-F), identifying them as ERES. GM130 is a Golgi matrix protein. At the onset of mitosis, GM130 is phosphorylated by CDC2 resulting in fragmentation of the Golgi apparatus and redistribution of the GM130 protein [27]. Almost all $(95 \pm 3 \%)$ CDC2-positive structures in 0 h GV oocytes also labeled for P-GM130 (Fig. 3A-C; IgG controls are shown in D-F). Calnexin is an ER-resident transmembrane protein, that localizes to the rough ER, but not to ERES $[26,30]$. Accordingly, we observed calnexin in a reticular pattern and at the nuclear envelope in $0 \mathrm{~h} G \mathrm{GV}$ oocytes (Fig. 3H, I). Consistent with its absence at ERES, calnexin was not found at CDC2-labeled cortical structures in any of the GV oocytes examined (Fig. 3G, I).
Finally, gamma-tubulin (Fig. 4A-C), which localizes to microtubule organizing centers, mitotracker (Fig. 4D-I), a marker for mitochondria, and NUP153 (Fig. 4J), one of the nuclear pore complex proteins that localizes to the nuclear membrane and to annulate lamellae, were not observed at CDC2-labeled structures. These results indicate that CDC2 accumulates in a specialized compartment in the smooth ER that comprises ERES.

\section{Inhibition of meiosis resumption prevents association of CDC2 with P-GMI30-labeled ERES}

In our lab, collecting, selecting, and denuding oocytes requires approximately $2.5 \mathrm{~h}$. Although oocytes in our experimental $0 \mathrm{~h}$ condition are still at the GV stage, they may already have resumed meiosis during this experimental interval. To prevent premature meiosis resumption during oocyte isolation, cumulus-oocyte complexes were collected in the presence of $100 \mu \mathrm{M}$ forskolin [31]. Forskolin stimulates the activity of adenylate cyclase, thus raising the intracellular CAMP concentration. Under these conditions, oocytes are maintained in prophase I arrest [32]. The presence of forskolin during oocyte isolation and denuding significantly reduced the occurrence of CDC2-labeling at the ERES cluster in GV stage oocytes (Fig. 5A), supporting the idea that CDC2 is recruited to ERES early after meiosis resumption. Since maintenance of meiotic arrest by forskolin is reversible [33], oocytes were isolated in the presence of forskolin, and examined at several time points after removal of forskolin from the culture media (forskolin chase). The percentage of GV oocytes containing CDC2-labeled ERES increased within $2 \mathrm{~h}$ of chase (Fig. 5B, D), followed by a decline to $~ 10 \%$ after $18 \mathrm{~h}$ of chase. In $0 \mathrm{~h}$ forskolin treated oocytes, the occurrence of P-GM130-labeled ERES equaled that in $0 \mathrm{~h}$ controls. A gradual decline in the percentage of GV oocytes containing P-GM130-labeled ERES was observed after forskolin removal (Fig. 5C, E). Combined, these results indicate that P-GM130 accumulates at ERES prior to meiosis resumption, and that $\mathrm{CDC} 2$ transiently associ-

Table I: Listing of markers used to establish the identity of cortical structures in immature oocytes.

\begin{tabular}{ccccc}
\hline Name & Type & Target & Reference & Present in a cortical structure \\
\hline CDC2 & mouse monoclonal antibody & Cell division cycle 2, catalytic subunit of MPF & {$[22]$} & + \\
PSTAIR & mouse monoclonal antibody & Cyclin binding domain in all Cdks & {$[23]$} & + \\
SEC23 & goat polyclonal antibody & SEC23, component of the coat protein II & {$[18]$} & complex \\
& & GMI30 phosphorylated on serine 25 & {$[27]$} & + \\
P-GMI30 & rabbit polyclonal antibody & Calnexin, transmembrane protein & {$[26]$} & + \\
Calnexin & rabbit polyclonal antibody & Gamma-tubulin, cytoskeletal component & {$[25]$} & - \\
Gamma-tubulin & rabbit polyclonal antibody & Oxidation within mitochondria & {$[28]$} & - \\
Mitotracker* & Fixable live cell dye & Nucleoporin I53 kDa & {$[29]$} & - \\
NUPI53 & mouse monoclonal antibody & Structural Golgi protein & {$[27]$} & - \\
GMI30 & mouse monoclonal antibody & Cyclin B, regulatory subunit of MPF & {$[22]$} & - \\
Cyclin B & mouse monoclonal antibody & SPDY, regulatory protein of CDC2 & {$[19]$} & - \\
SPDY & rabbit polyclonal antibody & - & + \\
\hline
\end{tabular}

* Stained by 30 min incubation in maturation medium prior to fixation. 


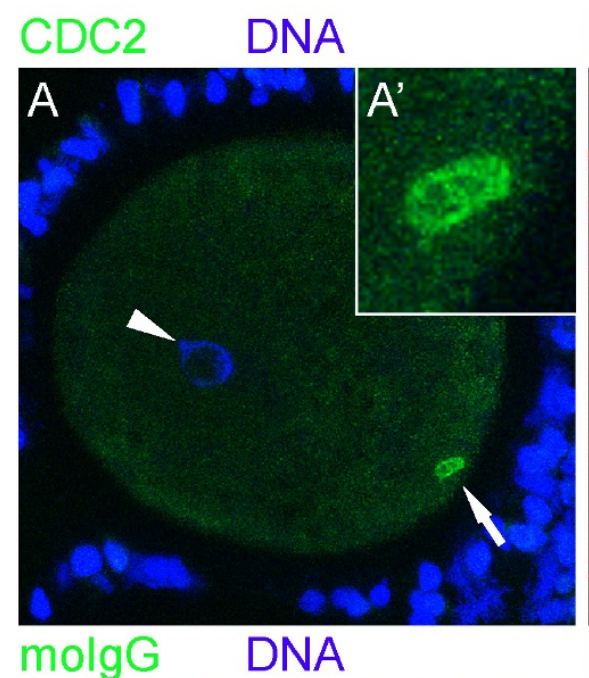

SEC23

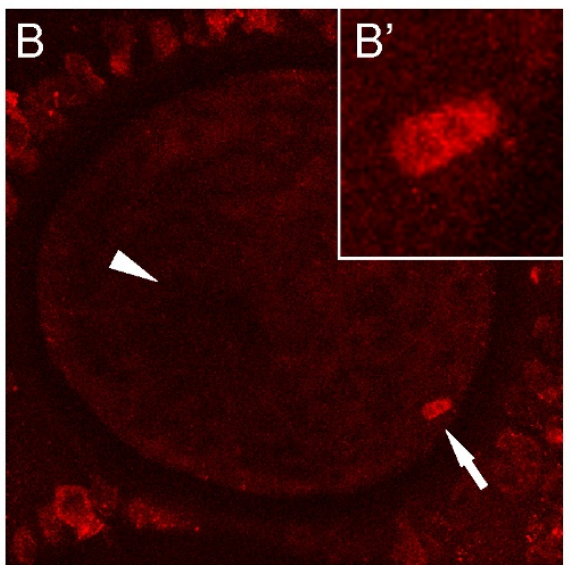

NGS
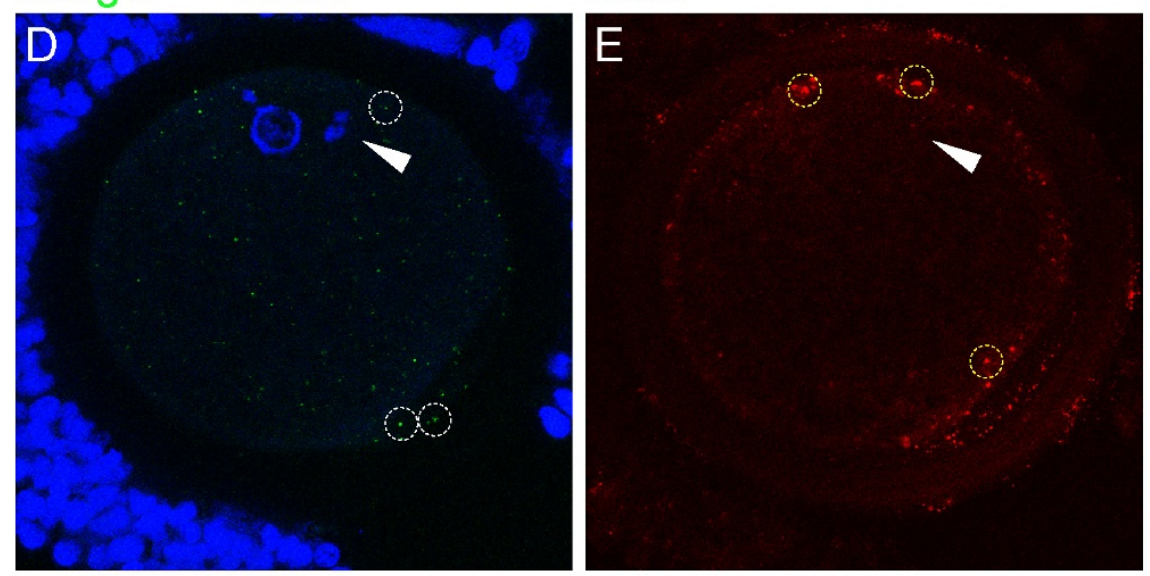

Merge

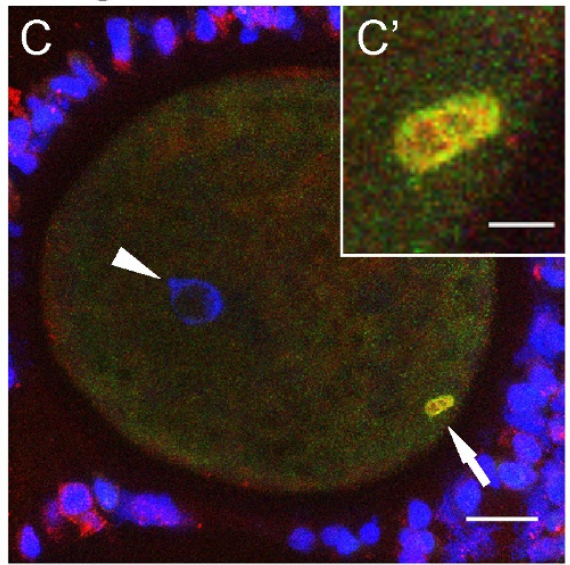

Merge

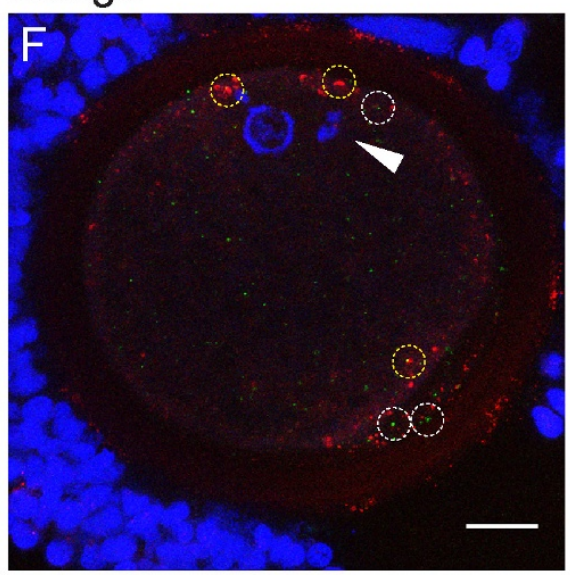

\section{Figure 2}

CDC2 associates with ER exit sites. (A-C) $0 \mathrm{~h}$ GV stage oocyte labeled for CDC2 (A, green), DNA (A, blue), and SEC23 (B, red). Colocalization (yellow) of CDC2 and SEC23 in a cortical domain in the ooplasm is evident in the merged image (C). (D-F) $0 \mathrm{~h} \mathrm{GV}$ stage oocyte from the same experiment as A-C, labeled with mouse lgG (molgG, D, green), DNA-marker (D, blue), and normal goat serum (NGS, E, red). Aspecific dots of molgG staining (examples are marked with white circles in D, F) and NGS (examples are marked with yellow circles in E, F) do not colocalize in the merged image (F). Confocal sections from an acquisition depth equivalent to $A-C$ are shown, and enhancements of D-F were identical to A-C. Images are Z-projections of 6 consecutive sections; scale bars represent $20 \mu \mathrm{m}$ in $\mathrm{C}$ and $\mathrm{F}$, and $5 \mu \mathrm{m}$ in $\mathrm{C}^{\prime}$. Arrows indicate the region of the oocyte that is shown enlarged in the insets $\left(A^{\prime}-C^{\prime}\right)$. Arrowheads denote the position of the GV.

ates with ERES just after the oocyte is released from the inhibitory influence of the follicle.

\section{Phosphorylated GMI30 is stored at ERES during maturation}

Given the role of CDC2 in phosphorylating the Golgi protein GM130, labeling for both GM130 and P-GM130 should provide information on the role of CDC2-labeled cortical domains in Golgi-protein redistribution during meiosis. To establish the distribution of GM130 and its phosphorylated form P-GM130 during oocyte maturation, oocytes were double-labeled for GM130 and PGM130 after 0,24 , and 44 h of IVM. GM130 staining revealed an intact Golgi apparatus and several GM130labeled areas in the periphery of $0 \mathrm{~h} \mathrm{GV}$ oocytes, whereas GM130 was not detected in CDC2-labeled ERES (Fig. 6A). As maturation progressed, GM130 staining in the oocyte was observed in progressively smaller and more dispersed fragments, whereas intact GM130-labeled Golgi complexes were observed in the cumulus cells (Fig. 6A, D, G). Staining for GM130 and P-GM130 did not overlap (Fig. 6C, F, I). At the GV stage, P-GM130 localized to a cortical domain (Fig. 6B, C). P-GM130 labeling persisted in the cortical domain in MI and MII stage oocytes, and increased in the ER as maturation progressed (Fig. 6E, $\mathrm{H}$, J). No P-GM130 staining was detected in the polar body 

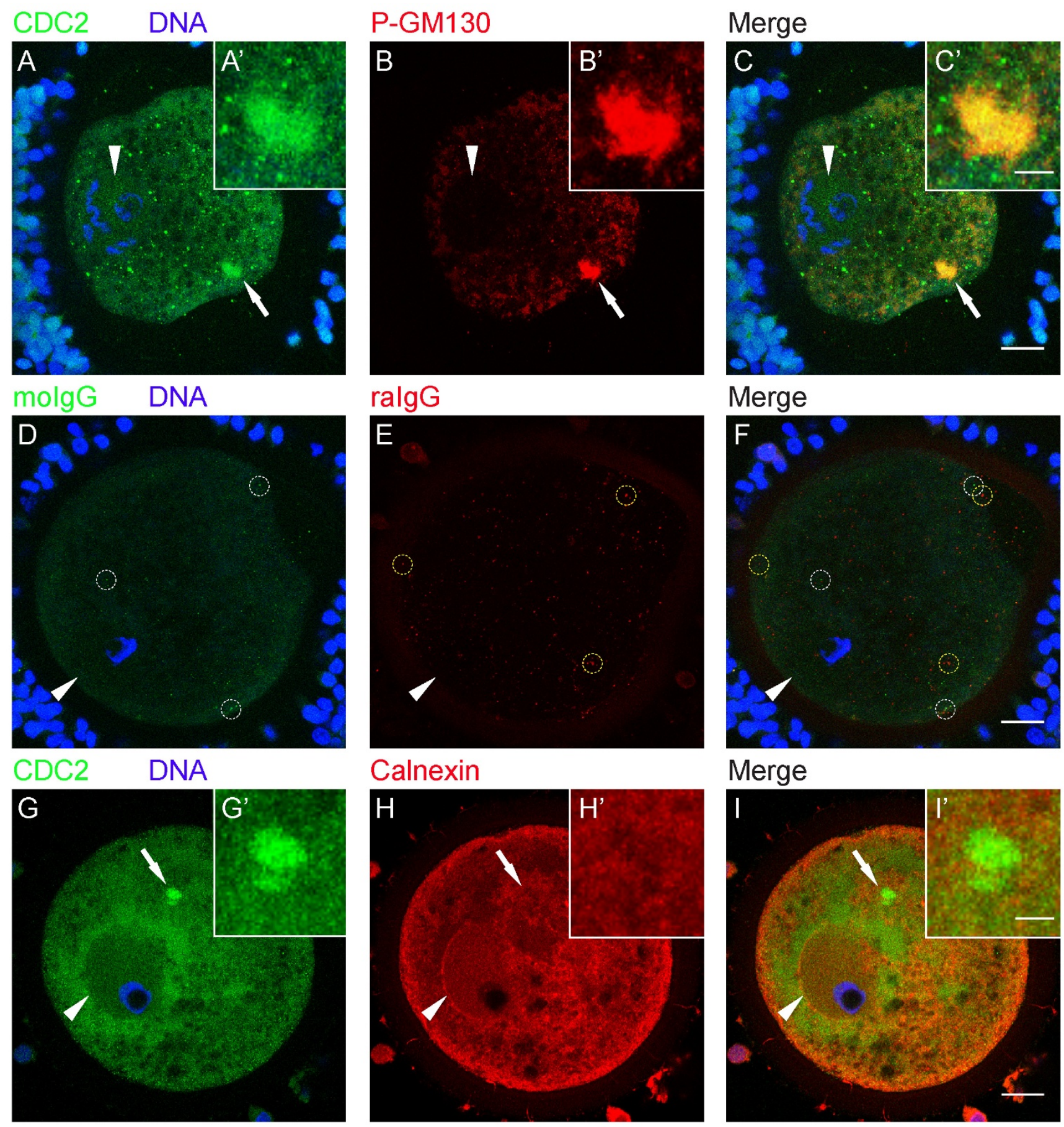

\section{Calnexin}

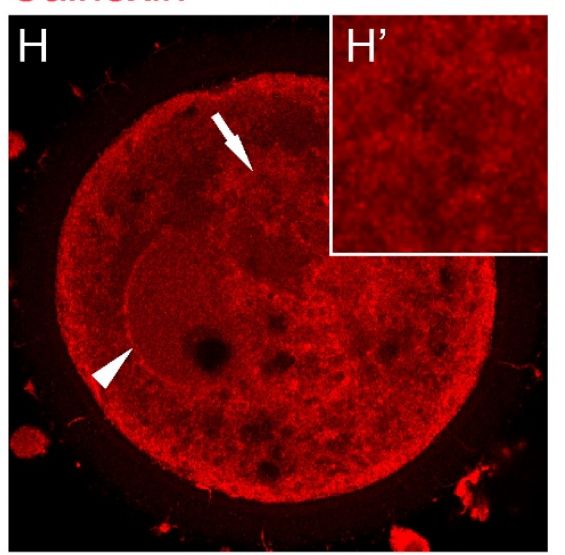

\section{Merge}

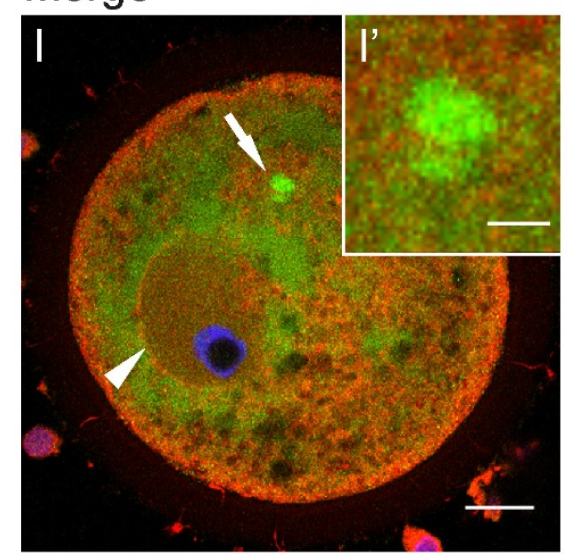

Figure 3 (see legend on next page) 
Figure 3 (see previous page)

The fragmented Golgi marker P-GMI30 colocalizes with CDC2 at ERES in immature oocytes. (A-C) 0 h GV stage oocyte labeled for CDC2 (A, green), DNA (A, blue), and phosphorylated GMI30 (B, red). Colocalization (yellow) of CDC2 and phosphorylated GMI30 in a cortical compartment in the ooplasm is evident in the merged image (C). (D-F) $0 \mathrm{~h} \mathrm{GV}$ stage oocyte from the same experiment as A-C, labeled with molgG (D, green), DNA-marker (D, blue), and rabbit lgG (ralgG, $E$, red). None of the aspecific dots (examples are marked with white circles in $D, F$ and yellow circles in $E, F$ ) colocalize in the merged image $(F)$. This control image was subjected to the same enhancements as $A-C$, and selected to show confocal sections from an equivalent acquisition depth. (G-I) $0 \mathrm{~h}$ GV stage oocyte labeled for CDC2 (G, green), DNA (G, blue), and the ERmarker calnexin $(\mathrm{H}$, red). No colocalization (yellow) of CDC2 and calnexin was observed in the merged image (I). Images are Z-projections of 6 consecutive sections (A-F), or 3 consecutive sections (G-I); scale bars represent $20 \mu \mathrm{m}$ in $\mathrm{C}$, F, and I, and 5 $\mu \mathrm{m}$ in $C^{\prime}$ and $I^{\prime}$. Arrows indicate the region of the oocyte that is shown enlarged in the insets $\left(A^{\prime}-C^{\prime}\right.$ and $\left.G^{\prime}-I^{\prime}\right)$. Arrowheads denote the position of the GV.

(Fig. 6H, I). These data indicate that during oocyte maturation, GM130 is stored in the ER in its phosphorylated form.

\section{CDC2 associates with SPDY at ERES}

The activity of CDC2 during cell division has been studied most extensively as MPF, a complex of CDC2 and cyclin B. Recently, evidence has been obtained that CDC2 activity in porcine oocytes can alternatively be controlled by SPDY, a protein with no homology to cyclin B [19]. Here, we used a combination of staining approaches to identify the regulatory component of CDC2 during early phases of maturation. Interestingly, we found that SPDY was present in CDC2-positive ERES in $0 \mathrm{~h} \mathrm{GV}$ oocytes (Fig. 7A-C). Since simultaneous labeling of oocytes for cyclin $\mathrm{B}$ and $\mathrm{CDC} 2$ was not possible due to the same host species of cyclin B and CDC2 antibodies, we used an alternative approach in which we identified ERES by the presence of P-GM130. Oocytes $(0 \mathrm{~h}, \mathrm{GV})$ double-labeled for PGM130 and cyclin B showed no cyclin B in P-GM130labeled ERES (0/21). Instead, about half of the oocytes (10/21) showed clear cyclin B labeling in the GV (Fig. 7DF). Consistent with these observations, anti-PSTAIR antibodies, which do not detect CDC2 when bound to cyclin B [23], labeled P-GM130-containing ERES (11/18), whereas PSTAIR was not observed in the GV of any of the oocytes examined $(0 / 18$; Fig. $7 \mathrm{G}-\mathrm{I})$. These results indicate that CDC2 at ERES associates with SPDY, but not cyclin B, at the onset of oocyte maturation.

\section{Discussion}

Here, we show that the cell-cycle regulating protein CDC2 transiently associates with a cluster of ERES at the onset of oocyte maturation, and propose that this association is involved in Golgi retention. Detailed microscopical analysis of large numbers of oocytes showed that during the initial phases of in vitro maturation, CDC2 localized to a large ( $\sim 7 \mu \mathrm{m}$ diameter) structure, that was exclusively observed in the cortex, in about a quarter of GV oocytes (Fig. 1A, F). The ERES marker SEC23 colocalized with CDC2 in about half of these cortical domains (Fig 2A-C), demonstrating that at least some of these CDC2-positive compartments consist of active ERES. A morphologically identical domain labeled for the CDC2 target protein PGM130 was observed in 80\% of 0 h GV stage oocytes (Fig. 6J), and almost all CDC2-labeled cortical domains also labeled for P-GM130. In addition to this morphological likeness, only one P-GM130-labeled domain was observed per oocyte and this domain was always found in a cortical position. These identical features of SEC23, CDC2, and/or P-GM130-labeled domains indicate that all of these domains were composed of ERES, albeit mostly inactive ERES, since the majority was devoid of SEC23 labeling.

Membrane trafficking, and thus association of SEC23 with ERES, is inhibited during mitosis in somatic cells [12-14], which may in part be due to disassembly of ERES [18]. Upon disassembly, ERES-resident proteins disperse into the ER where they remain until the ERES are reformed at the start of interphase [18]. Our results support this view, since P-GM130 disperses from the ERES-containing domain into the ER prior to GVBD (Fig. 5C, E and fig. 6B, $\mathrm{E}, \mathrm{H})$. However, P-GM130 localization at the cortical domain was observed in $>80 \%$ of oocytes at MI and MII (Fig. 6J). No difference in either morphology or position within the oocyte could be observed throughout maturation using P-GM130 as a marker for this domain (Fig. 6). Therefore, it can be inferred that the P-GM130-labeled domain is composed of ERES throughout maturation. When compared to ERES described in most somatic cells and bovine oocytes $[6,18]$, the cortical domain in porcine oocytes is exceptionally large. Since SEC23 was not found outside the cortical domain (Fig. 2B), we conclude that most if not all ERES are clustered together in the cortex at this stage. The presence of this single cluster of ERES has not been reported before and appears to be a unique feature of oocytes.

During pre-GVBD IVM, the percentage of GV oocytes containing CDC2-labeled ERES decreased significantly (Fig. $1 D)$. When the onset of maturation was prevented by iso- 

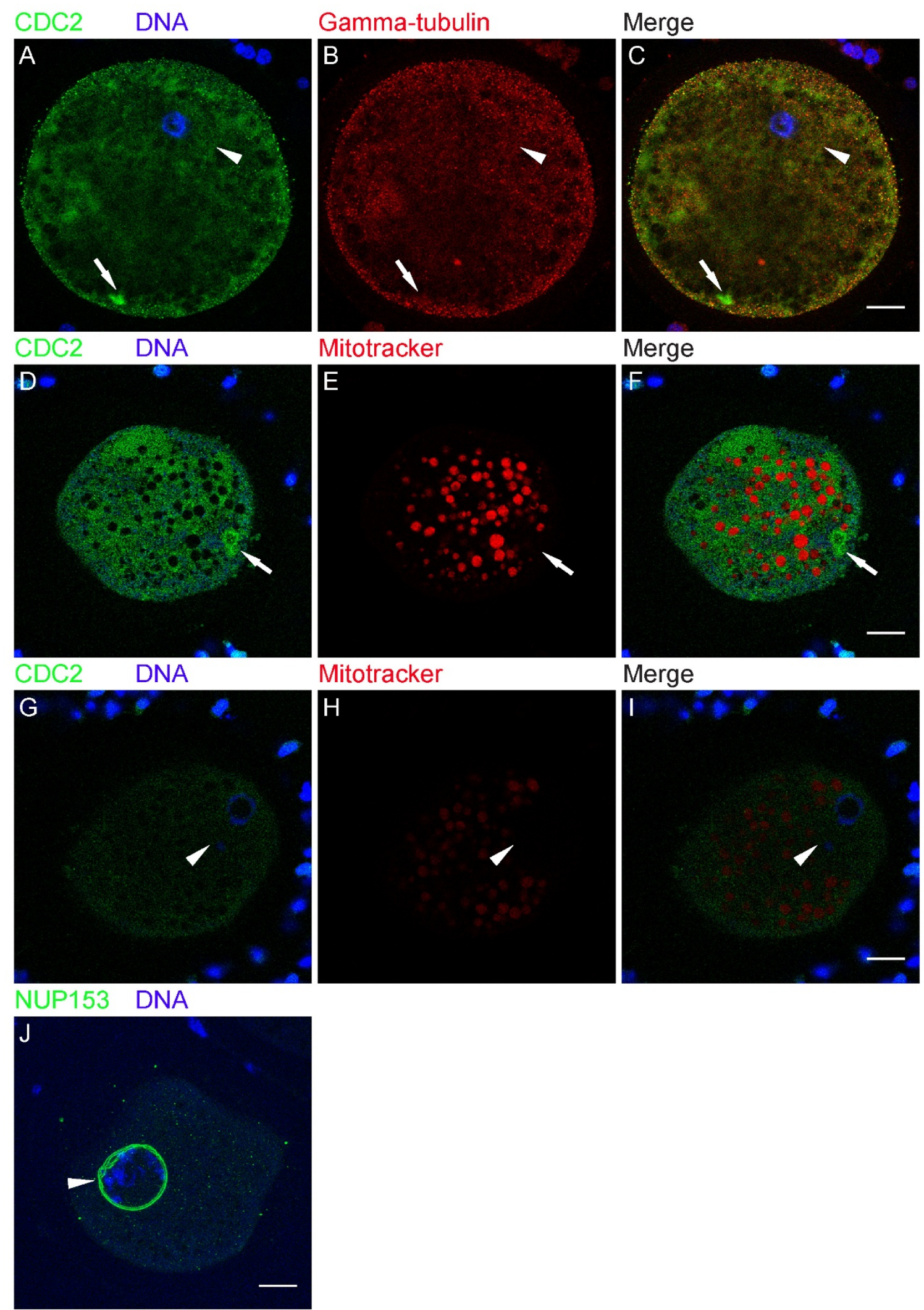

Figure 4 (see legend on next page) 
Figure 4 (see previous page) Gamma-tubulin, mitochondria, and NUP I 53 do not associate with ERES. (A-C) 0 h GV stage oocyte labeled for CDC2 (A, green), DNA (A, blue), and gamma-tubulin (B, red). The CDC2-labeled ERES cluster did not label with gamma-tubulin (C). (D-F) $0 \mathrm{~h} \mathrm{GV}$ stage oocyte labeled for CDC2 (D, green), DNA (D, blue), and mitochondria, using the mitochondrial marker mitotracker (E, red). Mitotracker did not label CDC2-positive ERES (F). (G-I) Confocal section through the same oocyte as in D-F showing the GV. Note that the much lower staining intensity in G-I compared to D-F is solely the result of a $\sim 65 \mu \mathrm{m}$ change in depth of imaging, since acquisition settings and image enhancement were identical between these images. (J) $0 \mathrm{~h}$ GV stage oocyte labeled for NUPI53 (green) and DNA (blue). None of the oocytes examined (0/I5) showed a cortical domain. The 3 separate double lines around the GV are the result of small size and shape changes between the 3 consecutive sections used to produce the image. Images are either Z-projections of 3 consecutive sections (A-C, J), or single sections (D-I); scale bars represent $20 \mu \mathrm{m}$ in C, F, I, and J. Arrows indicate CDC2-labeled ERES, and arrowheads denote the position of the GV.

lating COCs in the presence of the adenylate cyclase-stimulating drug forskolin, the occurrence of CDC2-labeled ERES was significantly decreased (Fig. 5A), demonstrating that CDC2 translocation to and accumulation at ERES is initiated upon release from meiotic inhibition. This CDC2 translocation may therefore constitute the first sign of meiosis resumption. CDC2 accumulation at ERES was transient since the occurrence of CDC2-labeled ERES increased within $2 \mathrm{~h}$ after release from forskolin-maintained meiotic arrest, and subsequently declined to a much lower level after $18 \mathrm{~h}$ of maturation (Fig. 5B, D). CDC2-labeled ERES could not be detected in oocytes that had undergone GVBD, indicating that CDC2 accumulation, and hence CDC2 activity, at ERES is specific for preGVBD stages. Transient localization of CDC2 at ERES would also explain the discrepancy between the occurrence of the CDC2- ( 25\%; Fig. 1F) and the P-GM130labeled ( $~ 80 \%$; Fig. 5C and 6J) ERES cluster in immature oocytes. These results corroborate the proposition that stage dependent translocation of CDC2 underlies specific spatial and temporal control of CDC2 activity within oocytes [34-36].

It is evident from studies on somatic cells that CDC2 is involved in fragmentation and partitioning of the Golgi during early phases of mitosis [27]. Golgi fragmentation is initiated by CDC2-dependent phosphorylation of the membrane-resident Golgi protein GM130 [17], followed by vesiculation of the collapsing cisternae [37]. In our experiments, the presence of forskolin during oocyte isolation did not change the occurrence of P-GM130-labeled ERES at $0 \mathrm{~h}$ (Fig. 5C, E), indicating that P-GM130 accumulation at ERES precedes meiosis resumption. The percentage of GV oocytes with a P-GM130-containing ERES cluster declined from $80 \%$ in forskolin-inhibited $0 \mathrm{~h}$ matured oocytes to $35 \%$ at 18 h of maturation after forskolin removal (Fig. 5C). When oocytes were matured for longer intervals, i.e. 24 or $44 \mathrm{~h}$, the percentage of oocytes showing a P-GM130-containing ERES cluster equaled that of the 0 h controls (Fig. 6J), whereas CDC2 did not localize at ERES clusters in MI (24 h) and MII (44 h) oocytes.
These data indicate that the transient presence of CDC2 is closely followed by a transient absence of P-GM130 at ERES, prior to GVBD. Given the role of CDC2 in controlling ERES disassembly at the onset of mitosis [18], we propose that CDC2 controls dispersion of P-GM130 from ERES into the reticular ER.

Two models on Golgi partitioning during cell division are currently prevalent in literature. One model claims that Golgi inheritance occurs independently from the ER by association of Golgi-derived vesicles with the developing spindle, which facilitates subsequent equal partitioning of these Golgi fragments during telophase [7]. In the other model, known as the ER-dependent model, Golgi proteins redistribute into the ER during metaphase and Golgi stacks are reformed in daughter cells upon reinitiation of ER export [8]. In our experimental model, most oocytes contained a P-GM130-labeled ERES cluster immediately after isolation and at MI and MII (Fig. 6J), whereas PGM130 was completely absent in the region surrounding the metaphase plates at both MI and MII (Fig. 6E, H). Staining of the non-phosphorylated form of GM130 in the oocyte showed an increasingly dispersed pattern as maturation progressed (Fig. 6A, D, G), and P-GM130 staining in the ER increased relative to staining in ERES (Fig. 6B, E, H), suggesting that phosphorylation of GM130 and redistribution of P-GM130 into the ER continues after meiosis resumption. Phosphorylation of Golgi-resident GM130 presumably triggers efficient translocation of this protein into the ER, because the distributions of GM130 and P-GM130 were mutually exclusive in porcine oocytes (Fig. 6C, F, I). Taken together, these results indicate that Golgi inheritance in oocytes occurs through redistribution of Golgi components into the ER, and thus support an ER-dependent model in oocytes.

Our data indicate that CDC2 at ERES was not complexed with cyclin B (Fig. 7D-I). Instead, we observed SPDY at CDC2-labeled ERES (Fig. 7A-C), suggesting that SPDY regulates $\mathrm{CDC} 2$ activity at ERES. Although we cannot conclude directly from our data that SPDY associates with 


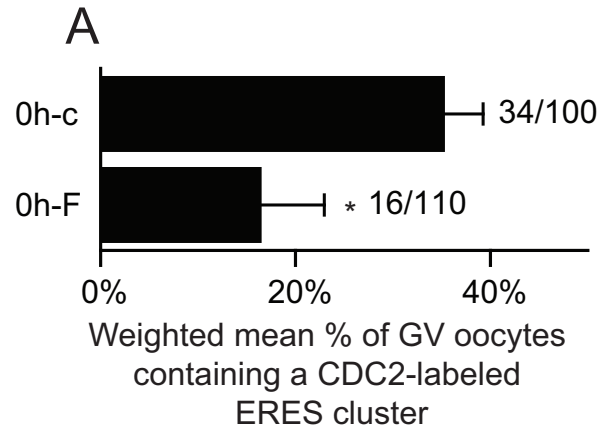

ERES cluster

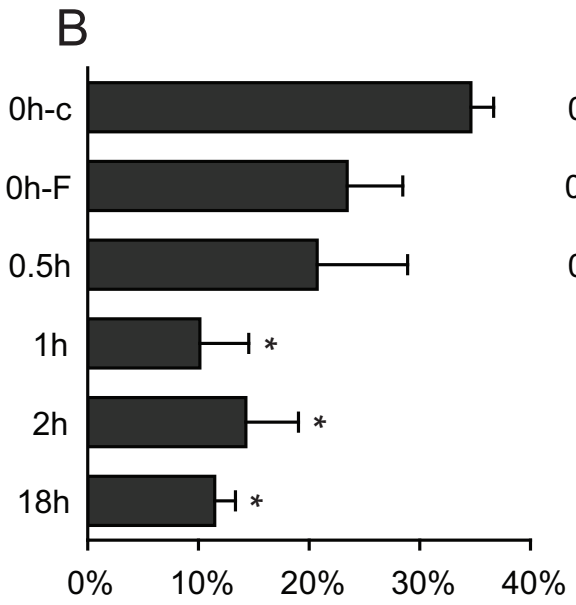

Weighted mean \% of GV oocytes containing a CDC2-labeled ERES cluster

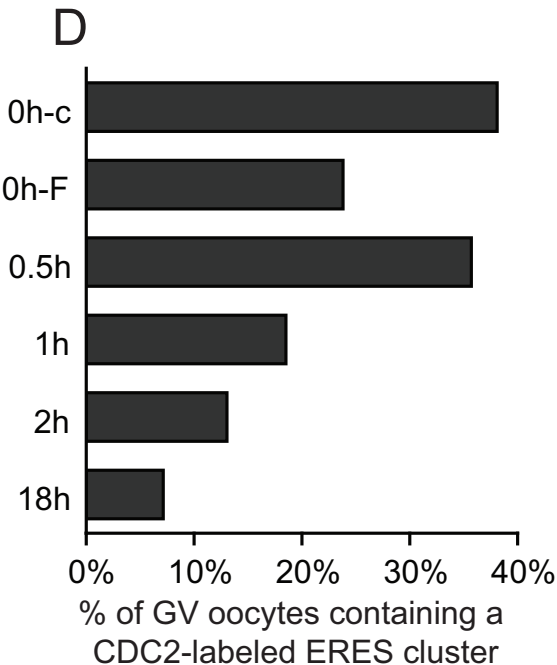

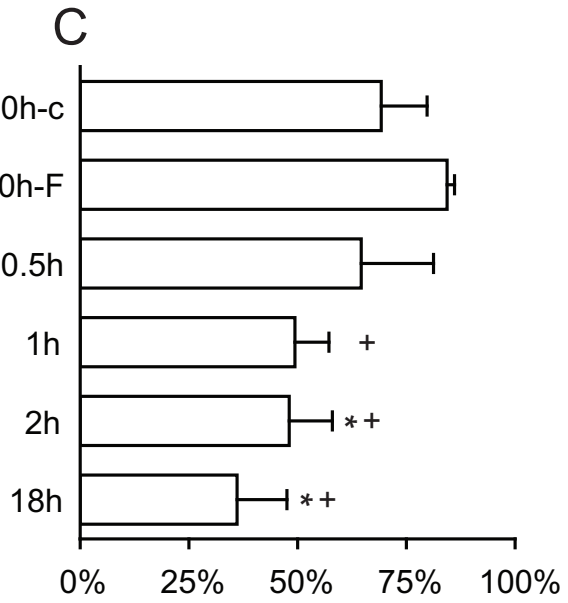

Weighted mean \% of GV oocytes containing a P-GM130-labeled ERES cluster

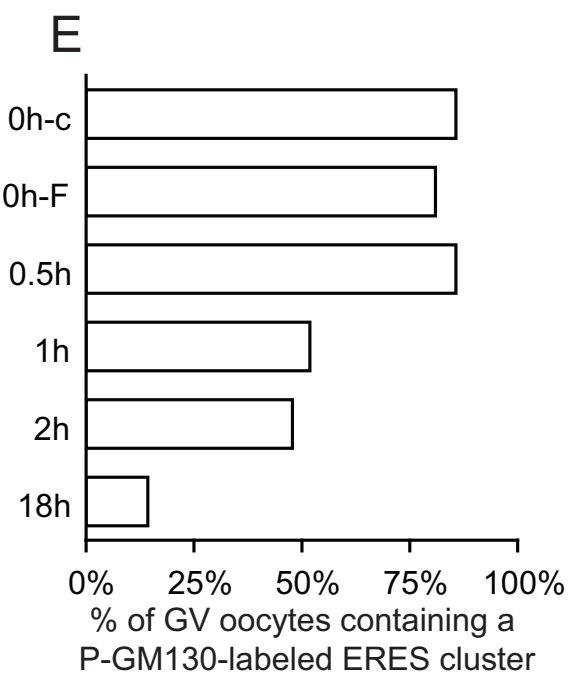

Figure 5

Inhibition of meiosis resumption prevents association of CDC2 with P-GMI30-labeled ERES. (A) Weighted mean percentage \pm weighted SEM of GV stage oocytes containing CDC2-labeled ERES clusters after treatment with either DMSO $(0 \mathrm{~h}-\mathrm{c})$ or $100 \mu \mathrm{M}$ forskolin $(\mathrm{Oh}-\mathrm{F})$ during the isolation procedure. Data from 3 separate experiments is shown and $*$ indicates significant difference $(P<0.05)$. Absolute numbers are shown next to the bars (number of positive oocytes/total number of oocytes). (B, C) Forskolin chase bar graphs ( $n=3 ; 20-30$ oocytes per group), showing the weighted mean percentage \pm weighted SEM of GV stage oocytes containing a cluster of ERES, labeled for CDC2 (B) and/or P-GMI 30 (C). In one of the experiments shown, an equal percentage of CDC2-labeled ERES was observed in Oh-F and Oh-c groups. As a result, the difference between Oh-c and Oh-F is significant in A, but not in B. The original dichotomous data (presence/absence of an ERES cluster) was analyzed in SPSS using binary logistic regression. All groups were compared to Oh-c and Oh-F conditions for a total of 10 comparisons per label. The familywise significance level was set to 0.05 , and was adjusted for pairwise comparisons using the Holm-Bonferroni procedure. Significant differences compared to 0 h-c or 0 h-F are indicated by * or + , respectively. (D, E) Representative example of a forskolin chase experiment from the series of experiments shown in $B$, C, showing the percentage of GV stage oocytes containing a cluster of ERES, labeled for CDC2 (D) and/or P-GMI30 (E). Note that the increase in the occurrence of CDC2-labeled ERES at $0.5 \mathrm{~h}$ after release from forskolin-maintained inhibition of maturation (D) is obscured in the chart showing combined data from three experiments $(B)$, because it occurred at varying time points. Conditions on the $y$ axis are: $0 \mathrm{~h}$ DMSO control $(0 \mathrm{~h}-\mathrm{c}), 0 \mathrm{~h}$ forskolin $(0 \mathrm{~h}-\mathrm{F})$, and $0.5, \mathrm{I}, 2$, and $18 \mathrm{~h}$ of maturation after forskolin removal $(0.5 \mathrm{~h} / \mathrm{l} \mathrm{h} /$ $2 \mathrm{~h} / \mathrm{l} 8 \mathrm{~h})$. 


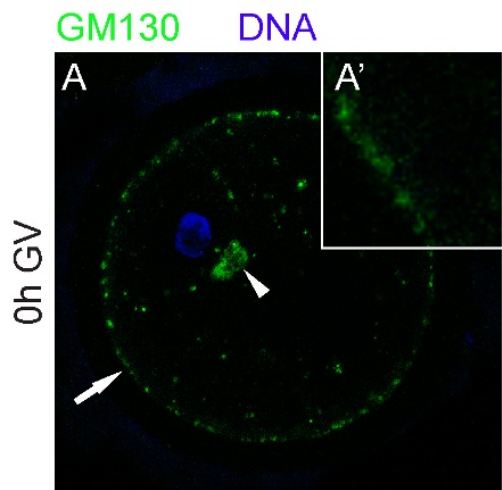

\section{P-GM130}
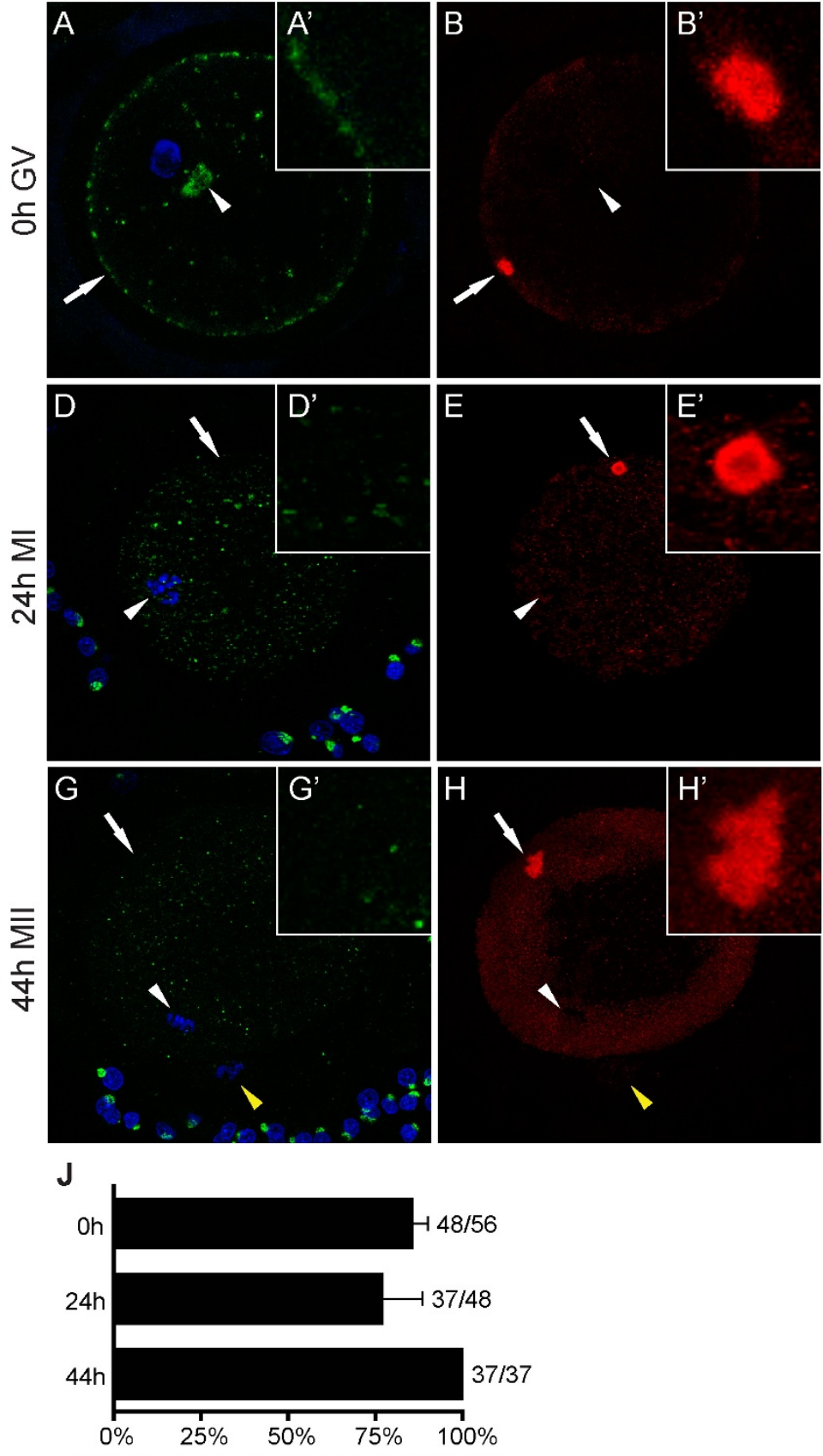

Weighted mean \% of oocytes containing a P-GM130-labeled ERES cluster

\section{Merge}
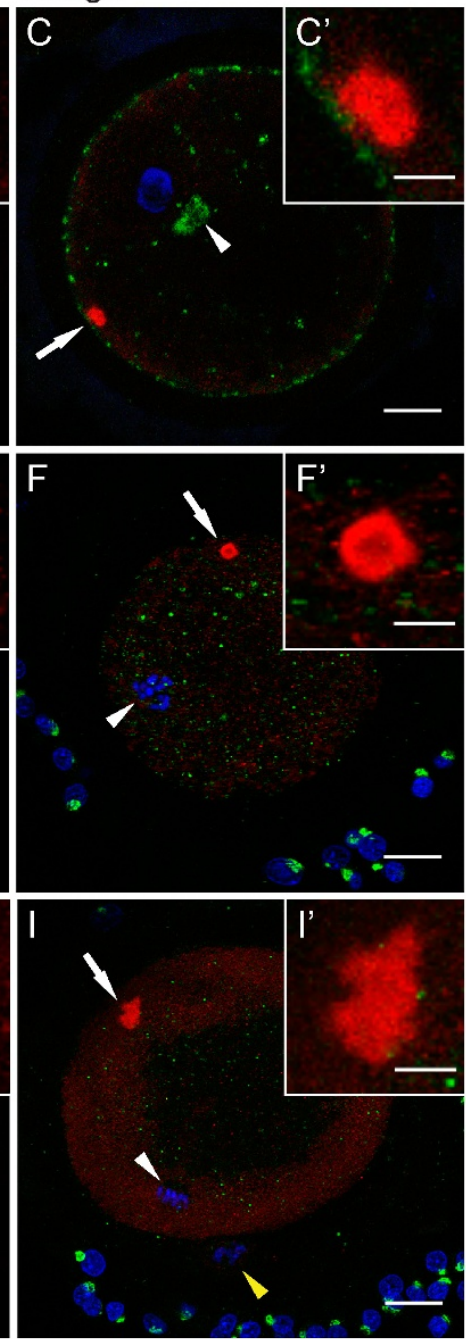

\section{Figure 6}

Phosphorylated GMI 30 is stored at ERES during maturation. Oocytes were stained for GMI 30 (green), P-GMI30 (red), and DNA (blue) at different maturation stages. (A-C) $0 \mathrm{~h}$ GV stage oocyte containing a perinuclear Golgi apparatus (arrowhead). (D-F) $24 \mathrm{~h}$ matured Ml oocyte containing a metaphase plate (arrowhead). (G-I) $44 \mathrm{~h}$ matured Mll oocyte showing the second metaphase plate (arrowhead) and a polar body (yellow arrowhead). Arrows indicate the area that is shown enlarged in the insets. Z-projections of 3 (A-F) or 6 (G-I) consecutive sections are shown; scale bars represent $20 \mu \mathrm{m}$ in C, F and $I$, and $5 \mu \mathrm{m}$ in $C^{\prime} F^{\prime}$ and $I^{\prime}$. Arrows indicate the region of the oocyte that is shown enlarged in the insets $\left(A^{\prime}-I^{\prime}\right)$. (J) Weighted mean percentage \pm weighted SEM of oocytes that contain a P-GMI30-labeled cortical domain at the indicated maturation times. Results from 2 independent experiments are shown. 

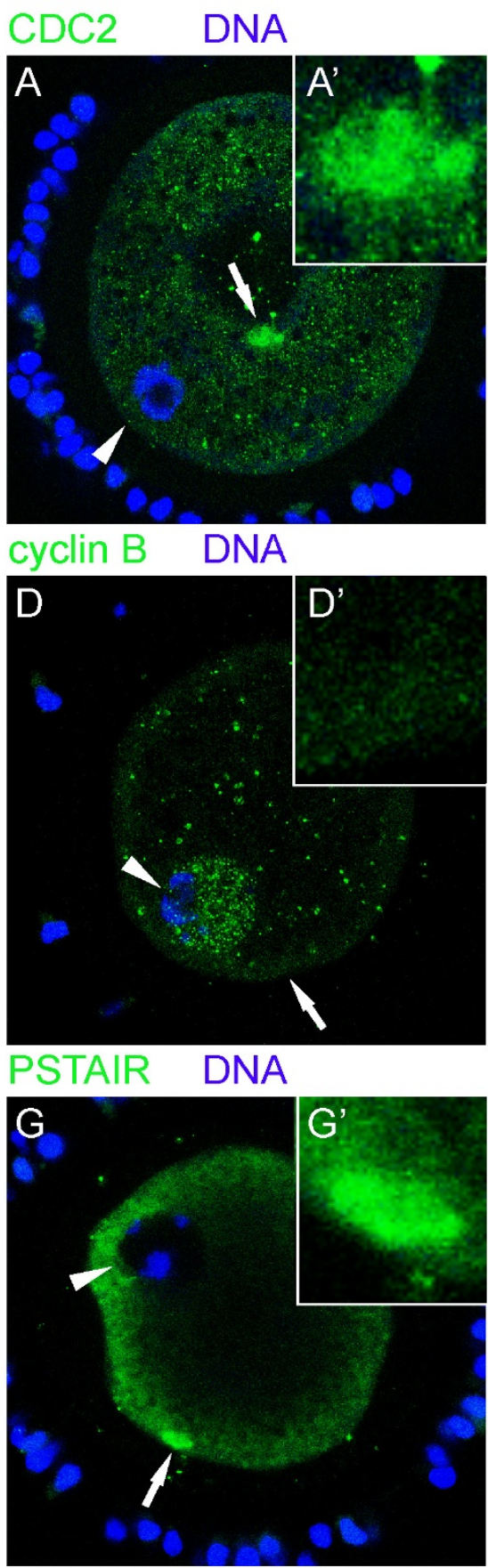

SPDY

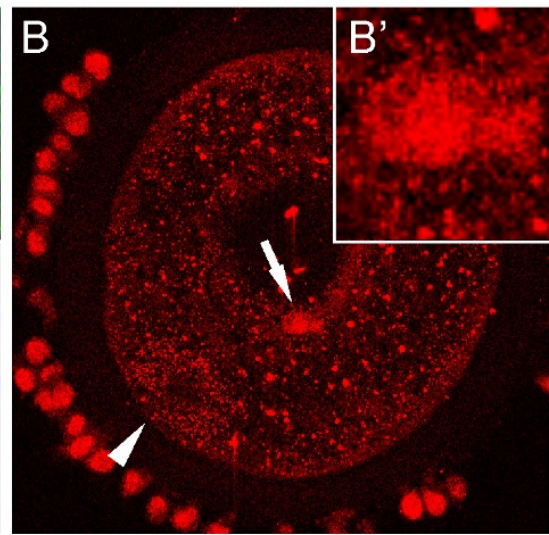

P-GM130

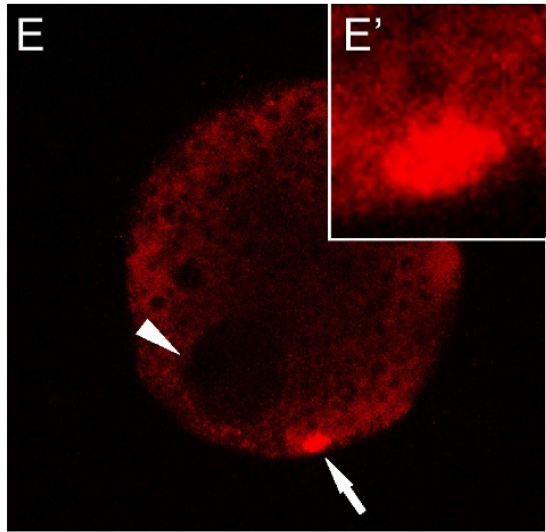

P-GM130

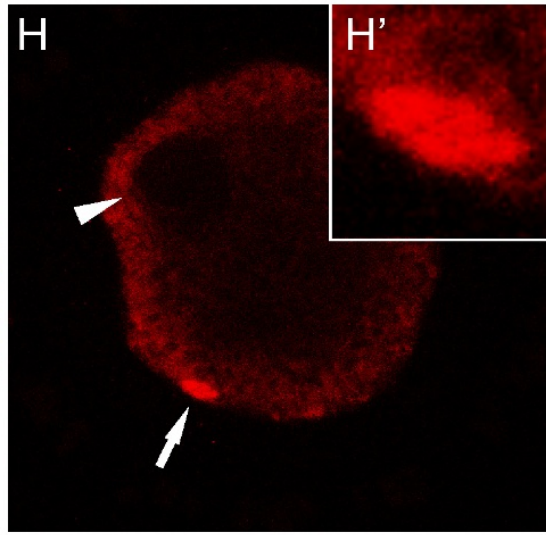

Merge

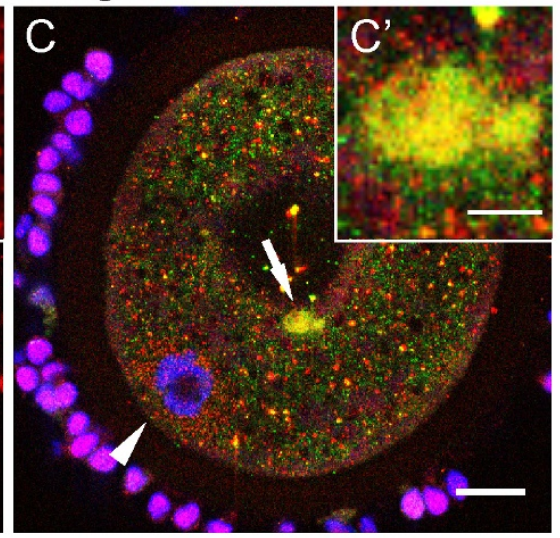

Merge

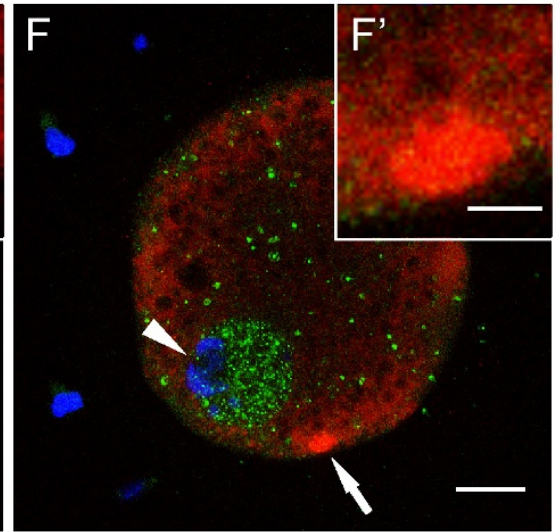

Merge

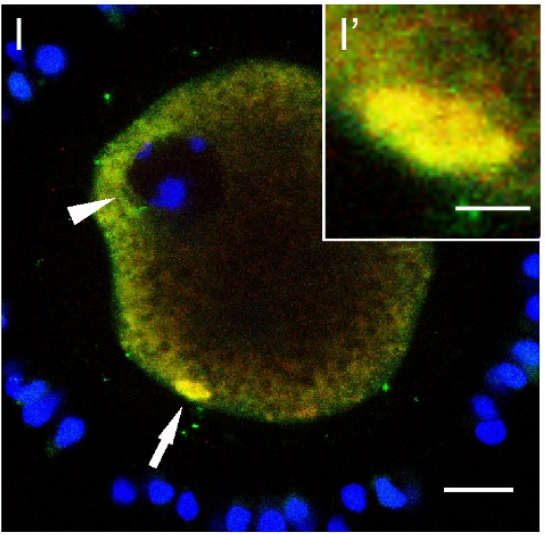

\section{Figure 7}

CDC2 associates with SPDY at ERES. (A-C) $0 \mathrm{~h}$ GV stage oocyte labeled for CDC2 (A, green), DNA (A, blue), and SPDY $(B$, red). Both CDC2 and SPDY localize to the same cortical domain (C). Note that the center of this oocyte is dented (the area that contains the arrow) causing the structure to appear in the middle of the oocyte, whereas it is located in the cortex. (D-F) 0 h GV stage oocyte stained for Cyclin B (D, green), DNA (D, blue), and P-GMI30 (E, red). Cyclin B did not localize to the P-GMI30-labeled cortical domain (F). (G-I) 0 h GV stage oocyte labeled for PSTAIR (G, green), DNA (G, blue), and PGMI30 (H, red). Spatial overlap of PSTAIR and phosphorylated GMI 30 staining (yellow) in a cortical domain is evident in the merged image (I). Images are Z-projections of $2(A-C)$ or $3(D-I)$ consecutive sections; scale bars represent $20 \mu \mathrm{m}$ in $C, F$, and $\mathrm{I}$, and $5 \mu \mathrm{m}$ in $C^{\prime}, F^{\prime}$, and $I^{\prime}$. Arrows indicate the region of the oocyte that is shown enlarged in the insets ( $\left.A^{\prime}-I^{\prime}\right)$. Arrowheads denote the position of the GV. 
CDC2 at ERES, additional evidence that SPDY may be a key regulatory protein of CDC2 upstream of MPF in porcine oocytes is provided by the observation that (1) CDC2/cyclin B activity can only be detected in a histone H1 kinase assay after 18-24 h of maturation [38-41] and that (2) injection of SPDY mRNA into oocytes accelerates oocyte maturation by stimulating MPF [21].

Our identification of a specialized cortical ERES-containing domain prompted us to compare it to similar structures described for other species. Morphologically, this cortical domain resembles Organized Smooth ER (OSER), which consists of stacked membrane arrays [42]. In our study, the ER-resident protein calnexin could not be detected in the CDC2-containing domain (Fig. 3G-I), indicating that this domain does not consist of reticular ER. In Xenopus laevis oocytes, cyclin B was found to localize to annulate lamellae, which may constitute one of the forms of OSER in immature oocytes [29]. Our studies show that neither the annulate lamellae marker NUP153 (Table 1, fig. 4J), nor cyclin B (Fig. 7A-C), localize to the cortical domain in immature porcine oocytes, suggesting that this domain does not consist of OSER or annulate lamellae. Primordial oocytes of several species contain an aggregate of organelles, the Balbiani body, which resembles the CDC2-labeled domain in size and in that there is only one of these bodies per oocyte. The Balbiani body contains components of several organelles including mitochondria, Golgi, and ER, and dissipates after the primordial stage [43]. P-GM130-labeled cortical domains were devoid of markers for intact Golgi (Fig. 6A, D, G) and mitochondrial markers (Table 1, fig. 4D-I), showing that the cortical domain and the Balbiani body are unrelated structures.

Based on observations in mitotic cells and our data from porcine oocytes, we hypothesize that prior to meiosis resumption, GM130 at the Golgi is phosphorylated by CDC2 $[17,27]$ and subsequently transferred to ERES. Upon initiation of oocyte maturation, $\mathrm{CDC} 2$ activity at ERES may result in dissociation of SEC23-containing coats and consequent cessation of vesiculation $[18,44]$. Other protein complexes that control ERES function may also be phosphorylated [45], allowing dispersion of PGM130 into the reticular ER, as observed for the ERES transmembrane marker Yip1A-GFP in CHO cells [18]. This mechanism could prevent recycling of GM130 back to the fragmenting Golgi and in this way facilitate complete Golgi breakdown. As pre-GVBD maturation proceeds, CDC2 is transported away from ERES (Fig. 1F), which may result in the renewed recruitment of P-GM130 to ERES (Fig. 6J). Since reformation of Golgi complexes at ERES has been observed in somatic cells [12-14], storage of P-GM130 in a cluster of ERES may allow for highly efficient and local reformation of the Golgi apparatus once the metaphase block of ER export is lifted after fertilization.

\section{Conclusion}

In this study, we have observed a novel domain in the cortex of porcine oocytes that comprises a cluster of ERES. We found that the well-known meiotic regulator CDC2 transiently localizes to this domain during pre-GVBD maturation, immediately after the oocyte is released from the inhibitory influence of the follicular environment. Our data further suggest that $\mathrm{CDC} 2$, in conjunction with its regulatory protein SPDY, plays a role in regulating storage of structural Golgi elements at this ERES cluster. The early role of the CDC2/SPDY complex described here adds to the available evidence [21] that points to a role for CDC2/ SPDY upstream of MPF during oocyte maturation. Finally, these findings demonstrate that pre-GVBD maturation comprises not only a set of changes in chromatin configuration [46], but also controlled and highly local events within the cytoplasm of the oocyte, that may be important in regulating the secretory system during the meiotic divisions.

\section{Methods \\ Reagents and antibodies}

All chemicals were purchased from Sigma Chemical Co. (St. Louis, MO, USA), unless otherwise indicated. The following antibodies and reagents were used (concentration or dilution and catalog number in brackets): mouse monoclonal anti-CDC2 $(1 \mu \mathrm{g} / \mathrm{ml}$; sc-54) and goat polyclonal anti-SEC23 (2 $\mu \mathrm{g} / \mathrm{ml}$; sc-12107) from Santa Cruz Biotechnologies (Santa Cruz, CA, USA); rabbit polyclonal antiCalnexin (1:250; SPA-860) from Stressgen Biotechnologies (San Diego, CA, USA); mouse monoclonal antiPSTAIR $(1 \mu \mathrm{g} / \mathrm{ml}$; ab10345, which is directed against EGVPSTAIREISLLKE, a conserved region in cyclindependent kinases (CDKs) [23,47]) and rabbit polyclonal anti-gamma-tubulin (1:1000; ab11321) from Abcam (Cambridge, UK); mouse monoclonal anti-NUP153 (4 $\mu \mathrm{g} / \mathrm{ml}$; MMS-102P) from Covance (Berkeley, CA, USA); mouse monoclonal anti-GM130 (1 $\mu \mathrm{g} / \mathrm{ml} ; \mathrm{G} 65120)$ and mouse monoclonal anti-cyclin B1 $(5 \mu \mathrm{g} / \mathrm{ml} ; 554179)$ from BD Biosciences (San Jose, CA, USA); rabbit polyclonal anti-SPDY $(2.2 \mu \mathrm{g} / \mathrm{ml} ; \mathrm{NB} 100-2521$, directed against a conserved region that is present in both isoforms) from Novus Biologicals (Littleton, CO, USA); Mitotracker Deep Red (200 nM; M22426), goat anti-mouse IgG alexa488, goat anti-rabbit IgG alexa568, and rabbit anti-goat IgG alexa488 $(20 \mu \mathrm{g} / \mathrm{ml} ; \mathrm{A} 11029, \mathrm{~A} 11036$, and A11078, respectively) from Molecular Probes (Eugene, OR, USA); donkey anti-mouse IgG Cy3 (6.25 $\mu \mathrm{g} / \mathrm{ml} ; 715-165-151)$ from Jackson ImmunoResearch Laboratories Inc. (West Grove, PA, USA); rabbit polyclonal anti-P-GM130 (1:100; detects GM130 phosphorylated on serine 25 [27]) was a 
generous gift from Dr. Martin Lowe (University of Manchester, UK).

\section{Collection, culture, and assessment of porcine cumulus oocyte complexes}

Cumulus-oocyte complexes (COCs) were collected from sow (Sus scrofa) ovaries, obtained from a slaughterhouse, by aspiration of 3-6 mm follicles [48] and subsequently selected using well established morphological criteria [49]. In vitro maturation (IVM) was performed as previously described [48], with the exception that media were not covered with oil. Briefly, COCs were collected in HEPES buffered M199 and washed in M199 (Gibco BRL) supplemented with $2.2 \mathrm{mg} / \mathrm{ml} \mathrm{NaHCO}, 0.1 \%$ (w/v) polyvinylpyrrolidone (PVP), $100 \mu \mathrm{M}$ cysteamine, $75 \mu \mathrm{g} / \mathrm{ml}$ potassium penicillin $\mathrm{G}$ and $50 \mu \mathrm{g} / \mathrm{ml}$ streptomycin sulphate (oocyte maturation medium; OMM) [49-51], and equilibrated in a $\mathrm{CO}_{2}$ incubator $\left(38.5^{\circ} \mathrm{C} ; 5 \% \mathrm{CO}_{2}\right)$ for at least $2 \mathrm{~h}$ before use. Selected COCs were cultured at $38.5^{\circ} \mathrm{C}$ under $5 \% \mathrm{CO}_{2}$ for $22 \mathrm{~h}$ in OMM supplemented with $0.05 \mathrm{IU} / \mathrm{ml}$ recombinant human FSH (rhFSH; a kind gift from Organon, Oss, the Netherlands). When COCs were cultured beyond $22 \mathrm{~h}$, the medium was replaced with OMM without FSH (24 h and $44 \mathrm{~h}$ culture conditions). Based on overall morphology and DNA staining pattern that was assessed by confocal laser scanning microscopy (see below), in vitro matured COCs were subdivided into three categories: germinal vesicle (GV), meiosis I (MI; indicated by the presence of a metaphase plate, anaphase I and telophase I stages were included in this group), and meiosis II (MII; as indicated by the presence of a metaphase plate and the first polar body). Oocytes that could not be scored or showed an aberrant morphology and did not fit any of the above criteria were excluded from statistical analyses.

\section{Inhibition of meiosis resumption by forskolin treatment}

COCs were kept in DMSO (control; 1:500) or $100 \mu \mathrm{M}$ forskolin (50 mM forskolin in DMSO diluted 1:500) [31] during isolation and selection. Next, oocytes were denuded in DMSO or forskolin, fixed, and stained for CDC2 and DNA. In forskolin chase experiments, COCs treated with forskolin during isolation and selection were washed and cultured in OMM without forskolin for $0.5,1$, 2, or $18 \mathrm{~h}$, and subsequently denuded and fixed. Finally, all groups were labeled for CDC2, P-GM130, and DNA, and the presence of structures was assessed using confocal laser scanning microscopy (as described below).

\section{Immunofluorescence staining for confocal laser scanning microscopy}

After culture, COCs were washed in $80 \mathrm{mM}$ PIPES, $5 \mathrm{mM}$ EGTA, $2 \mathrm{mM} \mathrm{MgCl}_{2}$, pH 6.8, supplemented with $0.3 \%$ (w/ v) PVP (PEM-PVP) at $37^{\circ} \mathrm{C}$. To minimize mechanical stress that accompanies denudation procedures, but maintain sufficient antibody penetration after fixation, oocytes were partially denuded by gentle pipetting in PEM-PVP supplemented with either $0.01 \%(\mathrm{w} / \mathrm{v})$ pronase (for $<22$ h cultured oocytes), or $0.1 \%$ (w/v) hyaluronidase (for $\geq 22$ h cultured oocytes). After washing in PEMPVP at $37^{\circ} \mathrm{C}$, oocytes were fixed in freshly prepared PEMPVP containing 4\% (v/v) paraformaldehyde (PF; Electron Microscopy Sciences, Hatfield, PA, USA) at room temperature (RT) for $1 \mathrm{~h}$. Fixed oocytes were stored in PEM-PVP containing $1 \%(\mathrm{v} / \mathrm{v}) \mathrm{PF}$ at $4^{\circ} \mathrm{C}$ for up to one week. For immunolabeling, oocytes were washed twice in PBS (0.1 $\mathrm{M}$; pH 7.4) containing $0.3 \%(\mathrm{w} / \mathrm{v}$ ) PVP (PBS-PVP) and once in PBS containing $0.1 \%(\mathrm{w} / \mathrm{v})$ saponin (PBS-S) for 5 min. Aspecific binding sites were blocked using 1\% (w/v) BSA and either $2 \%(\mathrm{v} / \mathrm{v})$ normal goat serum, or $2 \%(\mathrm{v} / \mathrm{v})$ normal horse serum (when goat polyclonal anti-SEC23 was used), both from Vector Lab (Burlingame, CA, USA), in PBS-S (blocking buffer) supplemented with $100 \mathrm{mM}$ glycine for $2 \mathrm{~h}$ at RT or overnight at $4{ }^{\circ} \mathrm{C}$. Subsequent immunolabeling steps were performed sequentially in blocking buffer for $1 \mathrm{~h}$ at RT and followed by three rinses in PBS-S for $10 \mathrm{~min}$ each. Primary and secondary antibody dilutions were centrifuged at $100,000 \mathrm{~g}$ for $1 \mathrm{~h}$ before use. As negative controls, all experiments included 5-10 oocytes that were incubated with purified mouse IgG combined with rabbit IgG or normal goat serum matching the host species of primary antibodies used as appropriate. Control IgG concentrations and serum dilutions were identical to primary antibodies in the same experiment. DNA was labeled with $10 \mu \mathrm{M}$ TO-PRO-3 iodide (Molecular Probes) in PBS-S for $20 \mathrm{~min}$. After a final three washes in PBS-S, oocytes were mounted in a $0.12 \mathrm{~mm} 8$ well Secure-Seal Spacer (Molecular Probes) on a coverslip, covered in Vectashield (Vector Lab), and sealed with a microscope slide (Superfrost Plus; Menzel, Braunschweig, Germany).

\section{Image acquisition and analysis}

Images were obtained through a $40 \times$ oil immersion objective (N.A. 1.3) using a BioRad Radiance $2100 \mathrm{MP}$ confocal system (Zeiss/BioRad, Hertfordshire, UK), equipped with 488,543 , and $637 \mathrm{~nm}$ lasers, or a Leica TCS SP2 confocal system (Leica Microsystems GmbH, Wetzlar, Germany), equipped with 488, 568, and 633 nm lasers. Dual and triple channel images were obtained by sequential scanning. ImageJ (NIH; http://rsb.info.nih.gov/ij/) image analysis software was used for qualitative analysis of images. Laser power and acquisition settings were adjusted to produce submaximal pixel values in the oocyte and settings used to image control IgG stainings were matched to the highest settings used to image primary antibody staining in the same experiment. Consecutive confocal sections were taken at $4 \mu \mathrm{m}$ intervals. Scoring of the structures described in this paper was performed by sequential scanning through oocytes from top to bottom in live view mode 
and noting the presence or absence of a structure. When a structure was present, sections through both structure and DNA were taken, whereas only DNA-containing sections were taken in oocytes that did not contain a structure. Images were selected based on the presence of DNA and a structure within 6 consecutive sections to clearly show both maturation stage and presence of a structure in a single image. Background subtraction and contrast/brightness enhancement (up to $\sim 20 \%$ enhancement using the maximum slider in imageJ) were performed on stacks of images, followed by maximum intensity Z-projection of consecutive sections to include both the structure and the region of the oocyte that contained chromatin. Contrast/ brightness enhancement of IgG controls was identical to images from the same experiment.

\section{SDS-PAGE and Western blot}

Oocytes were completely denuded by vortexing for 15 min in PBS-PVP containing protease inhibitor (Roche Molecular Biochemicals, Almere, the Netherlands). Denuded oocytes were separated from cumulus cells by two consecutive washes. Leftover cumulus cells were collected by centrifugation of the cumulus-containing suspension for $15 \mathrm{~min}$ at $16,000 \mathrm{~g}$, and oocytes were collected by centrifugation for $5 \mathrm{~min}$ at 16,000 g. After removal of the supernatant, the cumulus cells and oocytes were snap-frozen in liquid nitrogen and stored at $-20^{\circ} \mathrm{C}$. Positive controls consisted of HeLa cells that were grown to near confluence and collected by centrifugation in PBS containing protease inhibitor (Roche). Cells were resuspended in $62.5 \mathrm{mM}$ Tris- $\mathrm{HCl}, 2 \%$ SDS, and 10\% glycerol (SDS sample buffer) to a concentration of $5 \times 10^{6}$ cells $/ \mathrm{ml}$ and snap-frozen in liquid nitrogen. After addition of SDS sample buffer to oocyte and granulosa cell samples, all samples were incubated at $100^{\circ} \mathrm{C}$ for $5 \mathrm{~min}$. Proteins were separated on $10 \%$ polyacrylamide gels (30 $\mu \mathrm{l} / \mathrm{slot})$ by SDS-PAGE and transferred to Polyvinylidene Fluoride membranes (Hybond-P; GE Healthcare Amersham Biosciences Europe Gmbh, Freiburg, Germany), which were subsequently blocked in PBS containing 0.1\% Tween-20 (PBST) supplemented with 5\% (w/v) non-fat milk powder (Protifar; Nutricia, Zoetermeer, the Netherlands), and incubated in antibody dilutions in PBST containing $0.5 \%$ (w/v) Protifar. Primary antibodies were probed using horseradish peroxidase-conjugated goat anti-mouse antibodies (Jackson ImmunoResearch Laboratories Inc., Westgrove, PA, USA) and detected by Supersignal west pico chemiluminescent substrate (Pierce Biotechnology, Rockford, IL, USA).

\section{Statistical analysis}

Data are presented as weighted mean percentage \pm weighted SEM of oocytes, unless otherwise indicated. Statistical analysis was performed on the original dichoto- mous data in SPSS 12.0 (SPSS Inc., Chicago, IL, USA) using chi-square tests unless otherwise indicated.

\section{Authors' contributions}

JJH carried out the immunofluorescence and western blot studies, performed statistical data analysis, and drafted the manuscript. WS, BC, DRG, and BAJR participated in design of the study, and helped with data interpretation and critical evaluation of the manuscript. TH conceived of the study, participated in its design and coordination, and helped draft the manuscript. All authors read and approved the final manuscript.

\section{Acknowledgements}

We wish to thank our colleagues at the department of Farm Animal Health for providing ovaries and helping to collect oocytes, A. de Graaff and R. Wubbolts at the Centre for Cellular Imaging for their technical assistance, and $\mathrm{H}$. Vernooij for statistical advice. Contributions to this work from lab technician Esther van 't Veld and master students Vasiliki Magoula, Nathalie Brabers, and Linda Thijssen are gratefully acknowledged. Finally, we would like to thank Dr. Lowe for generously providing us with P-GMI 30 antibody.

\section{References}

I. Handel MA, Eppig J]: Sexual dimorphism in the regulation of mammalian meiosis. Curr Top Dev Biol 1998, 37:333-358.

2. Brevini TA, Cillo F, Antonini S, Gandolfi F: Cytoplasmic remodelling and the acquisition of developmental competence in pig oocytes. Anim Reprod Sci 2006, 98:23-38.

3. Sun QY, Wu GM, Lai L, Park KW, Cabot R, Cheong HT, Day BN, Prather RS, Schatten H: Translocation of active mitochondria during pig oocyte maturation, fertilization and early embryo development in vitro. Reproduction 200I, 122:155-163.

4. Mehlmann LM, Terasaki M, Jaffe LA, Kline D: Reorganization of the endoplasmic reticulum during meiotic maturation of the mouse oocyte. Dev Biol 1995, 170:607-6I5.

5. Moreno RD, Schatten G, Ramalho-Santos J: Golgi apparatus dynamics during mouse oocyte in vitro maturation: effect of the membrane trafficking inhibitor brefeldin A. Biol Reprod 2002, 66: 1259-1266.

6. Payne C, Schatten G: Golgi dynamics during meiosis are distinct from mitosis and are coupled to endoplasmic reticulum dynamics until fertilization. Dev Biol 2003, 264:50-63.

7. Shorter J, Warren G: Golgi architecture and inheritance. Annu Rev Cell Dev Biol 2002, 18:379-420.

8. Colanzi A, Suetterlin C, Malhotra V: Cell-cycle-specific Golgi fragmentation: how and why? Curr Opin Cell Biol 2003, I 5:462-467.

9. Shima DT, Cabrera-Poch N, Pepperkok R, Warren G: An ordered inheritance strategy for the Golgi apparatus: visualization of mitotic disassembly reveals a role for the mitotic spindle. J Cell Biol 1998, 141:955-966.

10. Jokitalo E, Cabrera-Poch N, Warren G, Shima DT: Golgi clusters and vesicles mediate mitotic inheritance independently of the endoplasmic reticulum. J Cell Biol 200I, 154:3 I7-330.

II. Seemann J, Pypaert M, Taguchi T, Malsam J, Warren G: Partitioning of the matrix fraction of the Golgi apparatus during mitosis in animal cells. Science 2002, 295:848-85I.

12. Altan-Bonnet N, Sougrat R, Liu W, Snapp EL, Ward T, LippincottSchwartz J: Golgi inheritance in mammalian cells is mediated through endoplasmic reticulum export activities. Mol Biol Cell 2006, I7:990-1005.

13. Prescott AR, Farmaki T, Thomson C, James J, Paccaud JP, Tang BL, Hong W, Quinn M, Ponnambalam S, Lucocq J: Evidence for prebudding arrest of ER export in animal cell mitosis and its role in generating Golgi partitioning intermediates. Traffic 200I, 2:321-335.

14. Zaal KJ, Smith CL, Polishchuk RS, Altan N, Cole NB, Ellenberg J, Hirschberg K, Presley JF, Roberts TH, Siggia E, et al:: Golgi membranes are absorbed into and reemerge from the ER during mitosis. Cell 1999, 99:589-60I. 
15. Kline D: Attributes and dynamics of the endoplasmic reticulum in mammalian eggs. Curr Top Dev Biol 2000, 50:125-154.

16. Dekel N: Cellular, biochemical and molecular mechanisms regulating oocyte maturation. Mol Cell Endocrinol 2005, 234: 19-25.

17. Lowe M, Rabouille C, Nakamura N, Watson R, Jackman M, Jamsa E, Rahman D, Pappin DJ, Warren G: Cdc2 kinase directly phosphorylates the cis-Golgi matrix protein $\mathrm{GMI} 30$ and is required for Golgi fragmentation in mitosis. Cell 1998, 94:783-793.

18. Kano F, Tanaka AR, Yamauchi S, Kondo H, Murata M: Cdc2 kinasedependent disassembly of endoplasmic reticulum (ER) exit sites inhibits ER-to-Golgi vesicular transport during mitosis. Mol Biol Cell 2004, I 5:4289-4298.

19. Karaiskou A, Perez LH, Ferby I, Ozon R, Jessus C, Nebreda AR: Differential regulation of Cdc2 and Cdk2 by RINGO and cyclins. J Biol Chem 200I, 276:36028-36034.

20. Naito K, Hawkins C, Yamashita M, Nagahama Y, Aoki F, Kohmoto K Toyoda Y, Moor RM: Association of p34cdc2 and cyclin BI during meiotic maturation in porcine oocytes. Dev Biol 1995, 1 68:627-634.

21. Kume S, Endo T, Nishimura Y, Kano K, Naito K: Porcine SPDYA2 (RINGO A2) stimulates CDC2 activity and accelerates meiotic maturation of porcine oocytes. Biol Reprod 2007, 76:440-447.

22. Beckhelling C, Perez-Mongiovi D, Houliston E: Localised MPF regulation in eggs. Biol Cell 2000, 92:245-253.

23. Yamashita M, Yoshikuni M, Hirai T, Fukada S, Nagahama Y: A Monoclonal Antibody Against the PSTAIR Sequence of p34 cdc2 Catalytic Subunit of Maturation-Promoting Factor and Key Regulator of the Cell Cycle. Dev Growth Differ 199I, 33:617-624 [http://www3.interscience.wiley.com/journal//20703374/abstract].

24. Schoevers EJ, Bevers MM, Roelen BA, Colenbrander B: Nuclear and cytoplasmic maturation of sow oocytes are not synchronized by specific meiotic inhibition with roscovitine during in vitro maturation. Theriogenology 2005, 63: IIII-II30.

25. Lee J, Miyano T, Moor RM: Spindle formation and dynamics of gamma-tubulin and nuclear mitotic apparatus protein distribution during meiosis in pig and mouse oocytes. Biol Reprod 2000, 62:1 I84-1192.

26. Hobman TC, Zhao B, Chan H, Farquhar MG: Immunoisolation and characterization of a subdomain of the endoplasmic reticulum that concentrates proteins involved in COPII vesicle biogenesis. Mol Biol Cell 1998, 9: I265-1278.

27. Lowe M, Gonatas NK, Warren G: The mitotic phosphorylation cycle of the cis-Golgi matrix protein GMI30. I Cell Biol 2000, | 49:34|-356.

28. Poot M, Zhang YZ, Kramer JA, Wells KS, Jones LJ, Hanzel DK, Lugade AG, Singer VL, Haugland RP: Analysis of mitochondrial morphology and function with novel fixable fluorescent stains. J Histochem Cytochem 1996, 44:1363-1372.

29. Beckhelling C, Chang P, Chevalier S, Ford C, Houliston E: Pre-M phase-promoting factor associates with annulate lamellae in Xenopus oocytes and egg extracts. Mol Biol Cell 2003, I 4: I I25-1 I37.

30. Mezzacasa A, Helenius A: The transitional ER defines a boundary for quality control in the secretion of ts 045 VSV glycoprotein. Traffic 2002, 3:833-849.

31. Fan HY, Li MY, Tong C, Chen DY, Xia GL, Song XF, Schatten H, Sun QY: Inhibitory effects of CAMP and protein kinase $C$ on meiotic maturation and MAP kinase phosphorylation in porcine oocytes. Mol Reprod Dev 2002, 63:480-487.

32. Han S], Conti M: New pathways from PKA to the Cdc2/cyclin $B$ complex in oocytes: Wee IB as a potential PKA substrate. Cell Cycle 2006, 5:227-23I.

33. Racowsky C: Effect of forskolin on maintenance of meiotic arrest and stimulation of cumulus expansion, progesterone and cyclic AMP production by pig oocyte-cumulus complexes. J Reprod Fertil 1985, 74:9-21.

34. Marangos P, Carroll J: The dynamics of cyclin B I distribution during meiosis I in mouse oocytes. Reproduction 2004, 128:153-162.

35. Terasaki M, Okumura E, Hinkle B, Kishimoto T: Localization and dynamics of Cdc2-cyclin $B$ during meiotic reinitiation in starfish oocytes. Mol Biol Cell 2003, 14:4685-4694.

36. Mitra J, Schultz RM: Regulation of the acquisition of meiotic competence in the mouse: changes in the subcellular locali- zation of cdc2, cyclin BI, cdc25C and weel, and in the concentration of these proteins and their transcripts. J Cell Sci 1996, 109(Pt 9):2407-24I5

37. Misteli T, Warren G: Mitotic disassembly of the Golgi apparatus in vivo. J Cell Sci 1995, 108:27I5-2727.

38. Wehrend A, Meinecke B: Kinetics of meiotic progression, $M$ phase promoting factor (MPF) and mitogen-activated protein kinase (MAP kinase) activities during in vitro maturation of porcine and bovine oocytes: species specific differences in the length of the meiotic stages. Anim Reprod Sci 200I, 66:175-184.

39. Kuroda T, Naito K, Sugiura K, Yamashita M, Takakura I, Tojo $H$ : Analysis of the roles of cyclin BI and cyclin B2 in porcine oocyte maturation by inhibiting synthesis with antisense RNA injection. Biol Reprod 2004, 70:154-159.

40. Shimada M, Zeng WX, Terada T: Inhibition of phosphatidylinositol 3-kinase or mitogen-activated protein kinase kinase leads to suppression of p34(cdc2) kinase activity and meiotic progression beyond the meiosis I stage in porcine oocytes surrounded with cumulus cells. Biol Reprod 200I, 65:442-448.

4I. Anger M, Klima J, Kubelka M, Prochazka R, Motlik J, Schultz RM: Timing of PIkI and MPF activation during porcine oocyte maturation. Mol Reprod Dev 2004, 69: I I-16.

42. Snapp EL, Hegde RS, Francolini M, Lombardo F, Colombo S, Pedrazzini E, Borgese N, Lippincott-Schwartz J: Formation of stacked ER cisternae by low affinity protein interactions. Cell Biol 2003, 163:257-269.

43. Kloc M, Bilinski S, Etkin LD: The Balbiani body and germ cell determinants: I 50 years later. Curr Top Dev Biol 2004, 59: I-36.

44. Stephens DJ: De novo formation, fusion and fission of mammalian COPII-coated endoplasmic reticulum exit sites. $E M B O$ Rep 2003, 4:210-217.

45. Mancias JD, Goldberg J: Exiting the endoplasmic reticulum. Traffic 2005, 6:278-285.

46. Sun XS, Liu Y, Yue KZ, Ma SF, Tan JH: Changes in germinal vesicle (GV) chromatin configurations during growth and maturation of porcine oocytes. Mol Reprod Dev 2004, 69:228-234.

47. Marcote MJ, Knighton DR, Basi G, Sowadski JM, Brambilla P, Draetta G, Taylor SS: A three-dimensional model of the $\mathrm{Cdc} 2$ protein kinase: localization of cyclin- and Sucl-binding regions and phosphorylation sites. Mol Cell Biol 1993, 13:5 I22-5I31.

48. Schoevers EJ, Colenbrander B, Roelen BA: Developmental stage of the oocyte during antral follicle growth and cumulus investment determines in vitro embryo development of sow oocytes. Theriogenology 2007, 67:1108-1122.

49. Abeydeera LR, Wang WH, Prather RS, Day BN: Maturation in vitro of pig oocytes in protein-free culture media: fertilization and subsequent embryo development in vitro. Biol Reprod 1998, 58:1316-1320.

50. Yamauchi N, Nagai T: Male pronuclear formation in denuded porcine oocytes after in vitro maturation in the presence of cysteamine. Biol Reprod 1999, 61:828-833.

5I. Grupen CG, Nagashima H, Nottle MB: Cysteamine enhances in vitro development of porcine oocytes matured and fertilized in vitro. Biol Reprod 1995, 53:173-178.

Publish with Biomed Central and every scientist can read your work free of charge

"BioMed Central will be the most significant development for disseminating the results of biomedical research in our lifetime. "

Sir Paul Nurse, Cancer Research UK

Your research papers will be:

- available free of charge to the entire biomedical community

- peer reviewed and published immediately upon acceptance

- cited in PubMed and archived on PubMed Central

- yours - you keep the copyright

Submit your manuscript here:

http://www.biomedcentral.com/info/publishing_adv.asp
BioMedcentral 